\title{
Household Overconfidence in the UK Housing Market
}

\author{
Soosung Hwang* \\ Sungkyunkwan University \\ Youngha $\mathrm{Cho}^{\#}$ \\ Oxford Brookes University \\ Jinho Shin \\ Sungkyunkwan University
}

\begin{abstract}
Using the Epstein-Zin utility in a consumption-based pricing model, we identify three explanatory variables required for the prediction of house prices - changes in consumption, stock returns, and changes in human capital. When overconfident households try to predict house prices using noisy signals for those three variables, their posterior expectation is biased such that they over-respond to those signals. UK households appear to over-respond to changes in consumption and human capital, but they do not over-respond to stock returns. Interestingly, we find that when household overconfidence is removed, house prices in London have been flat since the 2008 financial crisis, indicating that the recent house price surge in London has been driven by household overconfidence in the outlook of the economy.
\end{abstract}

Keywords: Overconfidence, Housing returns, Bayesian updating, Epstein-Zin utility JEL code: R3, G12

* College of Economics, Sungkyunkwan University, 25-2 Sungkyunkwan-Ro, Jongno-gu, Seoul 110745, South Korea. Tel: +82 (0)2 760 0489, Fax: +82 (0)2 744 5717, Email: shwang@ @kku.edu.

\# Department of Real Estate and Construction, Oxford Brookes University, Gipsy Lane. Oxford, OX3 0BP, UK, Tel: +44(0)1865 483941, Fax: +44(0)1865 483927, Email: ycho@ brookes.ac.uk

- College of Economics, Sungkyunkwan University, 25-2 Sungkyunkwan-Ro, Jongno-gu, Seoul 110745, South Korea. Tel: +82 (0)2 3788 2334, Fax: +82 (0)2 3788 2350, Email:

jinho.shinn@gmail.com. 


\title{
Household Overconfidence in the UK Housing Market
}

\begin{abstract}
Using the Epstein-Zin utility in a consumption-based pricing model, we identify three explanatory variables required for the prediction of house prices - changes in consumption, stock returns, and changes in human capital. When overconfident households try to predict house prices using noisy signals for those three variables, their posterior expectation is biased such that they over-respond to those signals. UK households appear to over-respond to changes in consumption and human capital, but they do not over-respond to stock returns. Interestingly, we find that when household overconfidence is removed, house prices in London have been flat since the 2008 financial crisis, indicating that the recent house price surge in London has been driven by household overconfidence in the outlook of the economy.
\end{abstract}

Keywords: Overconfidence, Housing returns, Bayesian updating, Epstein-Zin utility JEL code: R3, G12 


\section{Introduction}

House prices play an important role in the economy because they affect households' consumption decisions by changing their perceived wealth or relaxing borrowing constraints (Kiyotaki and Moore, 1997; Case, Quigley, and Shiller, 2005; Helbling and Terrones, 2003; Iacoviello, 2005; Campbell and Cocco, 2007). In particular, the effects of house price busts on consumption and financial systems are nearly twice as long and large as those of equity price busts (Helbling and Terrones, 2003), and more than two thirds of systemic banking crises in recent decades have been preceded by boom-bust patterns in house prices. ${ }^{1}$

Given the importance of the housing sector in the real economy, many studies have investigated irrational price movements in housing markets. Irrational bubbles (Escobari, Damianov, and Bello, 2012; Kivedal, 2013), media hype (Case and Shiller, 2003; Shiller, 2005; Hirshleifer, Subrahmanyam, and Titman, 2006; Bucchianeri, 2011), inelasticity of supply (Glaeser, Gyourko, and Saiz, 2008), aggressive mortgage lending (Pavlov and Wachter, 2011), inflation and nominal interest rates (Brunnermeier and Julliard, 2008), and herding (Shiller, 2005; Hott, 2012) have been proposed to explain mispricing in housing markets. Mispricing in housing markets might be more severe than seen in other asset classes because of the shortsale restriction and illiquidity, which make housing markets buoyant (Miller, 1977; Ofek and Richardson, 2003; Scheinkman and Xiong, 2003).

In this study, we investigate whether overconfidence among households contributes to mispricing in housing markets. Although the conventional economics assumes that people are rational, many studies in psychology and economics provide theoretical and empirical evidence of overconfidence that affects asset prices (Barberis, Schleifer, and Vishny, 1998; Odean, 1998;

\footnotetext{
1 http://www.imf.org/external/np/speeches/2014/060514.htm.
} 
Daniel, Hirshleifer and Subrahmanyam, 1998, 2001; Hong and Stein, 1999; Gervais and Odean, 2001; Scheinkman and Xiong, 2003; Statman, Thorley, and Vorkink, 2006; Chuang and Lee, 2006; Epstein and Schneider, 2008; Merkle, 2013; Hwang, 2015). We investigate whether house prices are affected when households become overconfident about the signals they use to predict house prices, to what signals they respond irrationally, and whether household overconfidence shows any regional differences.

For this purpose, we first propose a pricing model that considers both intertemporal substitution and risk aversion in the utility proposed by Epstein and Zin (1989, 1991). Three core explanatory variables are identified by the consumption-based equilibrium asset pricing model for the explanation of residential property returns: changes in consumption, stock returns, and changes in human capital. ${ }^{2}$ For households that predict house prices, however, those three explanatory variables are not directly available and thus must be predicted. When households are overconfident about the signals they use to update their prior beliefs about those explanatory variables, their posterior expectation becomes biased to make their signals appear more accurate than they really are (Daniel, Hirshleifer, and Subrahmanyam, 1998, 2001; Gervais and Odean, 2001; Epstein and Schneider, 2008). We propose a measure for those overconfidence biases during their Bayesian updating process.

Using residential property return data from nine UK regions together with other macroeconomic variables, we find that UK households are overconfident in noisy signals for consumption growth and human capital growth. However, we do not find evidence that their expectations about housing returns are affected by household overconfidence in the noisy signals of stock returns. This is partly because stock returns are highly volatile, and thus the

\footnotetext{
2 These variables have been proposed in the literature to explain asset prices. For example, see Mayers (1972), Stambaugh (1982), Jagannathan and Wang (1996), Campbell (1996), Lettau and Ludvigson (2001), Lustig and Van Nieuwerburgh (2008), Bansal, Kiku, Shaliastovich, and Yaron (2014), and Caporale and Sousa (2015).
} 
signals are not really useful in predicting housing returns.

We show empirical evidence that UK households are overconfident in the housing market, which is consistent with the evidence for other asset classes, e.g., financial markets (Daniel, Hirshleifer, and Subrahmanyam, 1998, 2001; Epstein and Schneider, 2008). For our sample period from 1980 to 2014, their expectations are on average positively biased through overconfidence by $0.19 \%$ per quarter above what the core explanatory variables suggest. Overconfidence was significant from the mid-1980s to the end of 1980s, and from the mid1990s to the end of the sample period, except for the financial crisis of 2008. Household overconfidence also shows clear regional difference. Households have been overconfidence in London and southern areas during the recent two decades since the mid-1990s. During the 1980s and 1990s, however, households in northern areas are relatively more overconfident than in southern areas.

Our study differs from previous studies that focus on the macroeconomic determinants of housing prices (Hwang and Quigley, 2006; Kallberg, Liu and Pasquariello, 2014), or the relationship between house prices and consumption (Lettau and Ludvigson, 2004; Case, Quigley and Shiller, 2005, 2011). Using a Bayesian framework to analyze how households process their information to predict housing markets, we identify which signals are likely to affect house prices via a well-known behavioral bias - overconfidence.

The remainder of this paper is organised as follows: in Section 2, we propose a model that shows bias in housing returns when households are overconfident in their interpretation of the signals they use to predict house prices. In the empirical test section, we estimate the effects of overconfidence in nine UK regions. Section 4 concludes the paper.

\section{Property Pricing Model with Household Overconfidence}


An asset pricing model should incorporate investors' willingness to change consumption over time and across different states of the world (Campbell, 1996; Campbell and Vuolteenaho, 2004; Lustig and Van Nieuwerburgh, 2008). The popular hyperbolic absolute risk aversion (HARA) class of utility functions has a limit as it does not properly distinguish between intertemporal substitution and risk aversion, and thus could not explain a large shift in consumption over time caused by a small increase in the interest rate (or discount factor) when the elasticity of intertemporal substitution in consumption is large.

It is important to consider intertemporal substitution in addition to risk aversion in the valuation of residential properties because the dwelling benefits, which compose a significant proportion of the total value relative to price appreciation, are interpreted as consumption goods (e.g., Piazzesi, Schneider, and Tuzel, 2007; Flavin and Nakagawa, 2008; Cho, Hwang, and Shin, 2015). This is in sharp contrast to other financial assets, such as equities, whose dividends have decreased for the past several decades (Fama and French, 2001) and thus their total returns are mainly driven by price changes rather than dividends. ${ }^{3}$

We first propose a pricing model for residential properties that specifies the elasticity of intertemporal substitution in consumption together with conventional risk aversion. We then show how to use the model to predict property prices in a Bayesian framework when households receive noisy signals. We also propose a test method to investigate which macroeconomic variables make households overconfident in the prediction of house prices.

\section{II.1 Asset Pricing Model with Intertemporal Substitution}

3 Dividends could be interpreted as additional benefits that shareholders can receive in addition to price changes, and thus they are similar to the dwelling benefits to households. 
Epstein and Zin $(1989,1991)$ add the elasticity of intertemporal substitution in consumption to the conventional power utility and propose a utility function for a representative agent, $u_{t}$;

$$
u_{t}=\left[(1-\beta) C_{t}^{(1-\gamma) / \theta}+\beta\left(E_{t}\left(u_{t+1}^{1-\gamma}\right)\right)^{1 / \theta}\right]^{\theta /(1-\gamma)},
$$

where $\theta=(1-\gamma) /\left(1-\frac{1}{\psi}\right), \quad \gamma$ is risk aversion, $\beta$ is time preference, and $C_{t}$ is consumption at time $t$. In this Epstein-Zin utility, the sensitivity of consumption change with respect to interest rate is captured by the elasticity of intertemporal substitution $\psi$. Suppose that the agent consumes from his wealth $\left(W_{t}\right)$ and invests the remainder in a wealth portfolio $p$, i.e., $W_{t+1}=\left(1+r_{p t+1}\right)\left(W_{t}-C_{t}\right)$, where $r_{p t+1}$ is the arithmetic return of the aggregate wealth portfolio at time $t+1$. Then, using dynamic programming arguments, Epstein and Zin show that the Euler equation for the above utility becomes

$$
E_{t}\left[M_{t+1}\left(1+r_{i t+1}\right)\right]=1 \text {, }
$$

in equilibrium where the entire perishable output is consumed and the bond market is cleared.

Here, the stochastic discount factor $M_{t+1}$ is defined as $M_{t+1} \equiv\left\{\beta\left(\frac{C_{t+1}}{C_{t}}\right)^{-1 / \psi}\right\}^{\theta}\left\{\frac{1}{1+r_{p t+1}}\right\}^{1-\theta}$, and $r_{i t+1}$ is the arithmetic return of residential property $i$.

When the portfolio return and consumption have a joint log-normal distribution, ${ }^{4}$ taking a natural log on both sides of the above equation yields:

$$
\ln E_{t}\left[M_{t+1}\left(1+r_{i t+1}\right)\right]=E_{t}\left[m_{t+1}+R_{i t+1}\right]+\frac{1}{2} \operatorname{Var}_{t}\left[m_{t+1}+R_{i t+1}\right]=0,
$$

where the $\log$ stochastic discount factor is $m_{t+1}=\ln M_{t+1}=\theta \ln \beta-\frac{\theta}{\psi} R_{c t+1}+(\theta-$

\footnotetext{
${ }^{4}$ When a random variable $X$ is conditionally lognormally distributed, its expected return is $\log E_{t}[X]=E_{t}[\log X]+\frac{1}{2} \operatorname{Var}_{t}[\log X]$ (Campbell, J.Y., A.W. Lo, and A.C. Mackinlay, 1997, pp. 306 307, The Econometrics of Financial Markets, Princeton University Press, Princeton, N.J.).
} 
1) $R_{p t+1}, R_{p t+1}$ and $R_{i t+1}$ are log-returns of the wealth portfolio and residential property $i$, respectively, i.e., $R_{p t+1}=\ln \left(1+r_{p t+1}\right)$ and $R_{i t+1}=\ln \left(1+r_{i t+1}\right)$, and $R_{c t+1}$ is the $\log$ consumption change, i.e., $R_{c t+1} \equiv \ln \frac{C_{t+1}}{C_{t}}=\ln \left(1+r_{c t+1}\right)$. Rearranging the equation above, the expected portfolio return can be written as

$$
E_{t}\left(R_{i t+1}\right)=-E_{t}\left(m_{t+1}\right)-\frac{1}{2}\left[\operatorname{Var}_{t}\left(m_{t+1}\right)+\operatorname{Var}_{t}\left(R_{i t+1}\right)+2 \operatorname{Cov}_{t}\left(m_{t+1}, R_{i t+1}\right)\right]
$$

Because the risk-free asset can be expressed as

$$
R_{f t+1}=-E_{t}\left(m_{t+1}\right)-\frac{1}{2} \operatorname{Var}_{t}\left(m_{t+1}\right)
$$

combining the two equations yields the consumption based model with the Epstein-Zin utility:

$$
E_{t}\left(R_{i t+1}-R_{f t+1}\right)+\frac{\sigma_{i t}^{2}}{2}=\theta \frac{\operatorname{Cov}_{t}\left(R_{i t+1}, R_{c t+1}\right)}{\psi}+(1-\theta) \operatorname{Cov}_{t}\left(R_{i t+1}, R_{p t+1}\right),
$$

where $\sigma_{i t}^{2}=\operatorname{Var}_{t}\left(R_{i t+1}\right)$. When $\theta=0$, or $\gamma=1$, the model is equivalent to the conventional CAPM of Sharpe (1964), Lintner (1965), and Mossin (1966): for example, $E_{t}\left(R_{i t+1}-\right.$ $\left.R_{f t+1}\right)+\frac{\sigma_{i t}^{2}}{2}=\gamma \operatorname{Cov}_{t}\left(R_{i t+1}, R_{p t+1}\right)$ when $\theta=0$. On the other hand when $\gamma=\frac{1}{\psi}$ or $\theta=1$, the model becomes the consumption-based CAPM of Breeden (1979) and Hansen and Singleton (1983), i.e., $E_{t}\left(R_{i t+1}-R_{f t+1}\right)+\frac{\sigma_{i t}^{2}}{2}=\gamma \operatorname{Cov}_{t}\left(R_{i t+1}, R_{c t+1}\right)$. In general, the consumption-based model with the Epstein-Zin utility suggests that the expected excess return of residential property $i$ is explained by both the elasticity of intertemporal substitution $(\psi$ via $\theta$ ) and risk aversion $(\gamma)$. The relative ratio of the two coefficients on the covariances in equation (6), i.e., $\frac{\theta / \psi}{1-\theta}=\frac{1-\gamma}{\psi \gamma-1}$, suggests that as the elasticity of intertemporal substitution increases ( $\psi$ increases), the expected excess return is affected more by the aggregate wealth portfolio than by consumption growth.

Converting to arithmetic returns, the expected excess return in equation (6) can be presented with betas: 


$$
E_{t}\left(r_{i t+1}-r_{f t+1}\right)=\beta_{i c t} \lambda_{c t}+\beta_{i p t} \lambda_{p t}
$$

where

$$
\beta_{i c t}=\frac{\operatorname{Cov}_{t}\left(r_{i t+1}, r_{c t+1}\right)}{\operatorname{Var}_{t}\left(r_{c t+1}\right)}, \quad \beta_{i p t}=\frac{\operatorname{Cov}_{t}\left(r_{i t+1}, r_{p t+1}\right)}{\operatorname{Var}_{t}\left(r_{p t+1}\right)}
$$

and

$$
\lambda_{c t}=\theta \frac{\operatorname{Var}_{t}\left(r_{c t+1}\right)}{\psi}, \lambda_{p t}=(1-\theta) \operatorname{Var}_{t}\left(r_{p t+1}\right)
$$

Because $\beta_{i c t}$ and $\beta_{i p t}$ are the coefficients from regressing excess returns on the change in consumption and the wealth portfolio return, respectively, a testable time series model for equation (7) can be presented as follows:

$$
r_{i t+1}-r_{f t+1}=\beta_{i 0 t}+\beta_{i c t} r_{c t+1}+\beta_{i p t} r_{p t+1}+\varepsilon_{i t+1}
$$

It becomes clear that $\beta_{i c t}$ and $\beta_{i p t}$, the two key components in the model with the EpsteinZin utility, appear as regression coefficients. The relationship between (7) and (8) is in fact analogous to the relationship between CAPM and the market model.

In any household portfolio, the wealth portfolio $p$ does include substantial human capital (Mayers, 1972; Jagannathan and Wang, 1996). In particular, the importance of human capital would be significant in pricing residential properties because major funding for residential properties, i.e., mortgage, is in fact backed by human capital. On the other hand, asset pricing is not sensitive to proxies of risky assets other than stocks (Stambaugh, 1982). Therefore, we assume that the wealth portfolio consists of stocks and human capital, following the literature (Campbell, 1996; Jagannathan and Wang, 1996; Lettau and Ludvigson, 2001; Lustig and Van Nieuwerburgh 2008; Bansal, Kiku, Shaliastovich, and Yaron, 2014; Caporale and Sousa, 2015). This leaves three variables (consumption change, stock return, and change in human capital) to explain the return of a residential property $i$ :

$$
r_{i t+1}-r_{f t+1}=\beta_{i 0 t}^{\prime}+\beta_{i c t}^{\prime} r_{c t+1}+\beta_{i s t}^{\prime} r_{a t+1}+\beta_{i h t}^{\prime} r_{h t+1}+\varepsilon_{i t+1}^{\prime},
$$


where $r_{s t+1}$ and $r_{h t+1}$ represent the stock return and change in human capital, respectively. In this study, we call those three variables the 'core' explanatory variables to differentiate them from other macroeconomic variables used to predict them.

\section{II.2 Bayesian Forecast with Noisy Signals}

The model in equation (9) is not directly applicable for the prediction of property $i$ 's excess return because the three core explanatory variables at time $t+1$ are not readily available to the agent at time $t$. The core explanatory variables must be estimated using available information. For example, macroeconomic forecasts or stock market outlooks would signal future consumption, labor markets, or stock markets. As in Epstein and Schneider (2008), suppose that the noisy signals for these core variables can be represented as

$$
S_{\bullet t}=r_{\bullet t+1}+\varepsilon_{\bullet t}
$$

where - denotes $c$ (consumption), $s$ (stock), or $h$ (human capital), and $\varepsilon_{\bullet t} \sim N_{i . i . d .}\left(0, \sigma_{\bullet t}\right)$, which is not correlated with $r_{\bullet t+1} . S_{\bullet t} \mathrm{~s}$ are noisy signals about consumption changes, stock returns, and human capital changes. Each signal includes the true future value at time $t+1$ and a noise term whose variances are unknown to the agent.

Upon receiving those noisy signals, the agent forms a posterior expectation of the excess return of residential portfolio $i$ as follows: ${ }^{5}$

$$
E_{t}\left(r_{i t+1}-r_{f t+1} \mid S_{\bullet t}\right)=E\left(r_{i t+1}-r_{f t+1}\right)+\gamma_{i c t}^{\prime} S_{c t}^{\prime}+\gamma_{i s t}^{\prime} S_{s t}^{\prime}+\gamma_{i h t}^{\prime} S_{h t}^{\prime}
$$

where $E\left(r_{i t+1}-r_{f t+1}\right)$ is the unconditional expected excess return of property $i, S_{\bullet t}^{\prime}=S_{\bullet t}-$

${ }^{5}$ If random variables $X$ and $Y$ follow a jointly normal distribution and their standard deviations and correlation are $\sigma_{X}, \sigma_{Y}$ and $\rho_{X Y}$, the conditional expected value of $X$ given $Y$ is

$$
E(X \mid Y)=E(X)+\rho_{X Y} \frac{\sigma_{X}}{\sigma_{Y}}\{Y-E(Y)\}
$$


$E\left(S_{\bullet t}\right)$, and $\gamma_{i \bullet t}^{\prime}=\frac{\operatorname{Cov}_{t}\left(r_{i t+1}, S_{\bullet t}^{\prime}\right)}{\operatorname{Var}_{t}\left(S_{\bullet t}^{\prime}\right)}=\frac{\operatorname{Cov}_{t}\left(r_{i t+1}, r_{\bullet t+1}\right)}{\operatorname{Var}_{t}\left(r_{\bullet t+1}\right)+\sigma_{\bullet t}^{2}}$ assuming that the signals are not crosscorrelated. ${ }^{6}$ Equation (11) shows how a representative agent uses signals to predict the future return.

It is clear that the variances of noises in the signals, i.e., $\sigma_{\bullet t}^{2} \mathrm{~s}$, reduce the explanatory power of the model. If the signals do not include noises, i.e., $r_{\bullet t+1} \mathrm{~s}$ are known in advance, then $\sigma_{\bullet t}^{2} \mathrm{~s}$ become zero and the posterior expectation becomes equivalent to the theoretical model in equation (7) or the testable model in (9). In practice where signals for future consumption, stock market, and human capital are noisy, equation (11) shows that the regression coefficients on the signals are biased downward, and thus the model can appear to perform poorly as noise becomes large.

\section{II.3 Bias in Posterior Expectation by Overconfidence}

A number of studies in psychology and economics suggest empirical evidence of behavioral biases in asset pricing (Barberis, Schleifer, and Vishny, 1998; Odean, 1998; Daniel, Hirshleifer and Subrahmanyam, 1998, 2001; Hong and Stein, 1999; Gervais and Odean, 2001; Scheinkman and Xiong, 2003; Baker and Wurgler, 2006: Epstein and Schneider, 2008). Overconfidence is a behavioral bias that has been extensively investigated by many studies in finance (for example, Gervais and Odean, 2001; Statman, Thorley, and Vorkink, 2006; Chuang and Lee, 2006; Merkle, 2013; Hwang, 2015). We investigate what happens in the above pricing model when households become overconfident in the noisy signals they use to predict housing returns.

In our study, overconfidence refers to a behavioral bias that arises when people believe

\footnotetext{
${ }^{6}$ Our empirical results show that the three core explanatory variables (consumption change, stock return, and change in human capital) are not correlated with each other. See the empirical test section for a further discussion.
} 
that the information they receive is more accurate than it really is (Griffin and Tversky, 1992; Moore and Healy, 2008). This type of overconfidence has been typically modelled in the literature by overprecision in signals: Daniel, Hirshleifer and Subrahmanyam (1998, 2001), Gervais and Odean (2001), and Epstein and Schneider (2008). Specifically, when an overconfident agent believes that the noisy signal he receives is more accurate than it really is, he underestimates the variance of noise in the signal. In our model presented in equation (11), overprecision can be modelled by underestimating the variances of the noises $\left(\sigma_{\bullet t}^{2} \mathrm{~s}\right)$.

Let $\sigma_{\bullet t}^{* 2} \mathrm{~s}$ denote the variances of noise under- or over-estimated because of over- or under-confidence. Then, the differences between the true variances and the biased variances, i.e., $\rho_{\bullet t} \equiv \sigma_{\bullet t}^{2}-\sigma_{\bullet t}^{* 2}$, represent biases in the precision of the noisy signals of the three core explanatory variables. The measures are positive if households are overconfident (overprecise) in their signals and negative when underconfidence (underprecision) arises. It is possible that overconfidence in one signal differs from that in others, and thus the signs of $\rho_{\bullet} t \mathrm{~s}$ are not necessarily the same. Empirically, this possibility allows an interesting test of which signals households to become more overconfident.

When households are overconfident in their signals, equation (11) can be represented as follows using the definition of the overconfidence measures:

$$
E_{t}^{C}\left(r_{i t+1}-r_{f t+1} \mid S_{c t}, S_{s t}, S_{h t}\right)=E\left(r_{i t+1}-r_{f t+1}\right)+\gamma_{i c t}^{*} S_{c t}^{\prime}+\gamma_{i s t}^{*} S_{s t}^{\prime}+\gamma_{i h t}^{*} S_{h t}^{\prime},
$$

where $E_{t}^{C}(\cdot)$ represents the biased posterior expectation operator in the presence of overconfidence, i.e., $\gamma_{i \bullet t}^{*}=\frac{\operatorname{Cov}_{t}\left(r_{i t+1}, S_{\bullet t}^{\prime}\right)}{\operatorname{Var}_{t}\left(S_{\bullet t}^{\prime}\right)-\rho_{i \bullet t}}$. Therefore, the distortion in the relationships between the expected property returns and the signals can be expressed as a difference between the coefficients defined in equations (11) and (12) as follows:

$$
\frac{\gamma_{i \bullet \bullet}^{*}-\gamma_{i \bullet t}^{\prime}}{\gamma_{\bullet \bullet t}^{\prime}}=\frac{\frac{\operatorname{Cov}_{t}\left(r_{i t+1}, s_{\bullet t}^{\prime}\right)}{\operatorname{Var}_{t}\left(S_{\bullet t}^{\prime}\right)-\rho_{\bullet t}}}{\frac{\operatorname{Cov}_{t}\left(r_{i t+1}, s_{\bullet t}^{\prime}\right)}{\operatorname{Var} t_{t}\left(s_{\bullet t}^{\prime}\right)}}-1=\frac{\rho_{\bullet t}}{\operatorname{Var}_{t}\left(S_{\bullet t}^{\prime}\right)-\rho_{\bullet t}}
$$


When the agent trades properties following the posterior in equation (12), the ex post property return would be affected by his behavioral bias. Let $r_{i t+1}^{*}$ be the realized return presented as the sum of the unbiased return $\left(r_{i t+1}\right)$ and the bias $\left(\eta_{i t+1}\right)$ caused by overconfidence: $r_{i t+1}^{*}=r_{i t+1}+\eta_{i t+1}$. Then, a testable model for equation (12) can be presented as

$$
r_{i t+1}^{*}-r_{f t+1}=\gamma_{i 0 t}+\gamma_{i c t} S_{c t}^{\prime}+\gamma_{i s t} S_{s t}^{\prime}+\gamma_{i h t} S_{h t}^{\prime}+e_{i t+1}^{*}
$$

where the regression coefficients are $\gamma_{i \bullet t}=\frac{\operatorname{Cov}_{t}\left(r_{i t+1}^{*}, s_{t}^{\prime}\right)}{\operatorname{Var}_{t}\left(r_{\bullet t+1}\right)+\sigma_{\bullet t}^{2}}=\frac{\operatorname{Cov}_{t}\left(r_{i t+1}, r_{\bullet t+1}\right)+\operatorname{Cov}_{t}\left(\eta_{i t+1}, \varepsilon_{\bullet t}\right)}{\operatorname{Var}_{t}\left(r_{\bullet t+1}\right)+\sigma_{\bullet t}^{2}}$. Unlike the ex ante coefficient $\gamma_{i \bullet t}^{*}$ in equation (12) where overconfidence is modelled by $\rho_{i \bullet t}$ in the denominator, overconfidence in the testable model appears as $\operatorname{Cov}_{t}\left(\eta_{i t+1}, \varepsilon_{\bullet}\right)$ in the numerator of the coefficient $\gamma_{i \bullet t}$. The denominators of the regression coefficients, if the coefficients are estimated with the realized core explanatory variables, are not biased any more. Under the assumption that the bias from overconfidence is fully reflected in property prices (if there is no difference between ex ante and ex post), the two coefficients $\left(\gamma_{i \bullet t}^{*}\right.$ and $\left.\gamma_{i \bullet t}\right)$ are the same because they represent return responses with respect to the noisy signals.

To calculate the bias $\left(\rho_{\bullet i t}\right)$ caused by overconfidence, note $\operatorname{Cov}_{t}\left(r_{i t+1}^{*}, r_{\bullet t+1}\right)=$ $\operatorname{Cov}_{t}\left(r_{i t+1}+\eta_{i t+1}, r_{\bullet t+1}\right)=\operatorname{Cov}_{t}\left(r_{i t+1}, r_{\bullet t+1}\right)$, where $r_{\bullet t+1}$ is the realization of the explanatory variables. This is true because the bias in the property return $\left(\eta_{i t+1}\right)$ is not created by $r_{\bullet t+1}$ but by underestimation (or overestimation) of $\sigma_{\bullet t}^{2}$. Therefore, the overconfidence in equation (12) can be expressed as

$$
\rho_{i \bullet t}=\operatorname{Var}_{t}\left(S_{\bullet t}^{\prime}\right)-\frac{\operatorname{Cov}_{t}\left(r_{i t+1}^{*}, r_{\bullet t+1}\right)}{\gamma_{i \bullet t}^{*}} .
$$

Substituting the coefficient $\gamma_{i \bullet t}=\frac{\operatorname{Cov}_{t}\left(r_{i t+1}^{*}, S_{\bullet t}^{\prime}\right)}{\operatorname{Var}_{t}\left(r_{\bullet t+1}\right)+\sigma_{\bullet t}^{2}}$ for $\gamma_{i \bullet t}^{*}$ in equation (15) gives the following overconfidence measures 


$$
\rho_{i \bullet t}=\operatorname{Var}_{t}\left(S_{\bullet t}^{\prime}\right)\left(1-\frac{\operatorname{Cov}_{t}\left(r_{i t+1}^{*}, r_{\bullet t+1}\right)}{\operatorname{Cov}_{t}\left(r_{i t+1}^{*}, S_{\bullet t}^{\prime}\right)}\right)=\operatorname{Var}_{t}\left(S_{\bullet t}^{\prime}\right)\left(1-\frac{\delta_{i \bullet t}}{\delta_{i \bullet t}^{\prime}}\right)
$$

where $\delta_{i \bullet t}=\frac{\operatorname{Cov}_{t}\left(r_{i t+1}^{*}, r_{\bullet t+1}\right)}{\operatorname{Var}_{t}\left(r_{i t+1}^{*}\right)}$ and $\delta_{i \bullet t}^{\prime}=\frac{\operatorname{Cov}_{t}\left(r_{i t+1}^{*}, S_{\bullet t}^{\prime}\right)}{\operatorname{Var}_{t}\left(r_{i t+1}^{*}\right)}$. The second term in equation (16) is

$$
1-\frac{\delta_{i \bullet t}}{\delta_{i \bullet t}^{\prime}}=\frac{\operatorname{Cov}_{t}\left(r_{i t+1}^{*}, S_{\cdot t}^{\prime}\right)-\operatorname{Cov}_{t}\left(r_{i t+1}^{*}, r_{\bullet t+1}\right)}{\operatorname{Cov}_{t}\left(r_{i t+1}^{*}, S_{\bullet t}^{\prime}\right)}=\frac{\operatorname{Cov}_{t}\left(\eta_{i t+1}, \varepsilon_{\bullet t}\right)}{\operatorname{Cov}_{t}\left(r_{i t+1}^{*}, r_{\bullet t+1}\right)+\operatorname{Cov}_{t}\left(\eta_{i t+1}, \varepsilon_{\bullet t}\right)},
$$

because $\operatorname{Cov}_{t}\left(r_{i t+1}^{*}, S_{\bullet t}^{\prime}\right)=\operatorname{Cov}_{t}\left(r_{i t+1}^{*}, r_{\bullet t+1}\right)+\operatorname{Cov}_{t}\left(r_{i t+1}^{*}, \varepsilon_{\bullet t}\right) \quad$ and $\operatorname{Cov}_{t}\left(r_{i t+1}^{*}, \varepsilon_{\bullet}\right)=$ $\operatorname{Cov}_{t}\left(\eta_{i t+1}, \varepsilon_{\bullet t}\right)$ which represents the effects of noise $\left(\varepsilon_{\bullet}\right)$ in a signal on the property return (the bias, $\left.\eta_{i t+1}\right)$. In other words, a positive (negative) covariance means that the agent is overconfident (underconfident) in the signal. When the agent is overconfident, for example, positive noise would contribute to an upward bias in property prices, whereas a negative signal would lower the property prices below their fundamental values. Therefore, we offer the following proposition.

Proposition 1 Overconfidence in a signal arises when $\frac{\delta_{i \bullet t}}{\delta_{i \bullet t}^{\prime}}<1$ where $\delta_{i \bullet t}$ and $\delta_{i \bullet t}^{\prime}$ are the regression coefficients in the following equations:

$$
\begin{aligned}
& r_{\bullet t+1}=\mu_{\bullet}^{\prime}+\delta_{i \bullet t} r_{i t+1}^{*}+e_{\bullet t+1}^{\prime}, \\
& S_{\bullet t}^{\prime}=\mu_{\bullet}^{\prime}+\delta_{i \bullet t}^{\prime} r_{i t+1}^{*}+e_{\bullet t+1}^{\prime}
\end{aligned}
$$

where $S_{\bullet t}^{\prime}, r_{\bullet t+1}$, and $r_{i t+1}^{*}$ are the noisy signal, the realized signal, and a property return, respectively. On the other hand, underconfidence arises when $\frac{\delta_{i \bullet t}}{\delta_{i \bullet t}^{\prime}}>1$. The test statistic for the null hypothesis $H_{0}: \delta_{i \bullet t}=\delta_{i \bullet t}^{\prime}$ can be obtained using the t-test:

$$
t=\frac{\hat{\delta}_{i \bullet t}-\hat{\delta}_{i \bullet t}^{\prime}}{\sqrt{s_{\hat{\delta}_{i \bullet t}}^{2}+s_{\widehat{\delta}_{i \bullet t}^{\prime}}^{2}}} \sim T\left(n_{1}+n_{2}-4\right),
$$

where $s_{\widehat{\delta}_{i \bullet t}}$ and $s_{\widehat{\delta}_{i \bullet t}^{\prime}}$ are the standard errors of $\hat{\delta}_{i \bullet t}$ and $\hat{\delta}_{i \bullet t}^{\prime}$ respectively. 
Proof The regression coefficients $\delta_{i \bullet t}$ and $\delta_{i \bullet t}^{\prime}$ are $\delta_{i \bullet t}=\frac{\operatorname{Cov}_{t}\left(r_{\bullet t+1}, r_{i t+1}^{*}\right)}{\operatorname{Var}_{t}\left(r_{i t+1}^{*}\right)}$ and $\delta_{i \bullet t}^{\prime}=$ $\frac{\operatorname{Cov}_{t}\left(S_{\cdot_{t}}^{\prime}, r_{i t+1}^{*}\right)}{\operatorname{Var}_{t}\left(r_{i t+1}^{*}\right)}$, respectively, from which $\frac{\delta_{i \bullet t}}{\delta_{i \bullet t}^{\prime}}$ can be calculated, as explained above. The test statistic for the null hypothesis $\mathrm{H}_{0}: \frac{\delta_{i \bullet t}}{\delta_{i \bullet t}^{\prime}}=1$ is equivalent to $H_{0}: \delta_{i \bullet t}=\delta_{i \bullet t}^{\prime}$.

\section{Empirical Tests}

In this section, we empirically investigate whether residential property prices are affected by household overconfidence in noisy signals. We first measure overconfidence and investigate in which core variables UK households are overconfident in the housing market. Then, we scrutinise the effects of overconfidence on housing returns.

\section{III.1 Data}

To measure overconfidence, we need various time series data, such as residential property returns, consumption changes, equity portfolio returns, and human capital changes. We use the Nationwide House Price Index for residential property returns, which provides quarterly indices for nine UK regions, East (E), East Midlands (EM), London (L), North East (NE), North West (NW), South East (SE), South West (SW), West Midlands (WM), and Yorkshire and the Humber ( $\mathrm{YH})$, as well as a nation-wide index (UK). ${ }^{7}$ The data used to

7 The Nationwide House Price Index is a seasonally adjusted house price index calculated using Nationwide lending data for residential properties at the post survey approval stage. Nationwide is a large provider of household savings and mortgages in the UK and is the largest building society in the world. The housing returns calculated with the house price index do not include rental income because household overconfidence is believed 
forecast consumption changes, equity returns, and human capital changes are explained below. The sample period is from 1980 to 2014. Considering the frequencies in macroeconomic variables and the illiquidity in property markets, we use quarterly data in the empirical tests.

\section{1) Variables for the prediction of consumption changes (CNSUMPTN_R)}

Previous studies have theoretically and empirically suggested various variables to predict consumption. Specifically, the permanent income hypothesis suggests that higher expected future income raises current consumption (e.g., Hall and Mishkin, 1982; Engel and Rogers, 2009). The wealth effect explains that consumption increases with UK house prices (Aron, Muellbauer, and Murphyi, 2006; Slacalek, 2009) or UK stock prices (Caporale and Sousa, 2015). Consumer confidence (Ludvigson, 2004) and GDP growth rate (De Giorgi and Gambetti, 2015) also affect consumption. Thus, we consider per capita labor income change (GDHI_UK), UK housing returns (R_UK), the FTSE All Share index return (FTSE_ALL_R), the consumer confidence index (CNFDNC), and GDP growth rate (GDP_R) to construct the signal for consumption changes.

\section{2) Variables for the prediction of stock returns (FTSE_ALL_R)}

The literature finds that stock returns can be predicted by variables, such as growth rate in industrial production (PRDCTN_A_R), unexpected change in inflation (CPI_R), credit spread (CRDT_SPRD), and term spread (TERM_SPRD) (Chen, Roll, and Ross, 1986). Other macroeconomic variables such as 10-year government bond yield (TB_10Y), unemployment rate (UMP), and change in sentiment index (SNTMNT_R) are also found to predict stock

to affect transaction prices rather than rental income. According to the US results of Davis, Lehnert, and Martin (2008), the rent-price ratio is sensitive to house prices. Moreover, regional rental income data are not available for the sample period. 
returns (e.g., Lettau and Ludvigson, 2001; Baker and Wurgler, 2006; Polk, Thompson, and Vuolteenaho, 2006; Kelly and Pruitt, 2013). Thus, we consider those variables as the components of the signal for stock returns.

\section{3) Variables for the prediction of regional human capital changes (GDHI_*)}

Human capital is not directly observable. However, in the literature, researchers have estimated changes in human capital using labor income: e.g., Jagannathan and Wang (1996), Lustig and Nieuwerburgh (2008), and Caporale, Sousa and Wohar (2016). Although the literature regards human capital change as a function of the state of the economy (Lustig and Nieuwerburgh, 2008; Bansal, Kiku, Shaliastovich, and Yaron, 2014), few studies have considered whether macroeconomic variables affect it. Giovanni and Matsumoto (2012) explain the relationship between human capital changes and several macroeconomic variables, finding that human capital changes correlate positively with housing returns, long-term bonds, and Treasury bills and negatively with stock returns. Therefore, we consider regional housing market returns $\left(\mathrm{R}_{-} *\right), 10$-year government bond yield $\left(\mathrm{TB} \_10 \mathrm{Y}\right)$, the three-month Treasury bill rate $\left(\mathrm{TB} \_3 \mathrm{M}\right)$, and FTSE index return (FTSE_ALL_R) as the components of the signal for human capital changes. We obtain changes in human capital and housing market returns for each region, which are represented by ' $*$ ' following the variable names.

\section{4) Statistical properties of the variables}

The basic statistical properties of housing returns in the nine UK regions as well as the entire UK are summarized in Table 1. The mean and standard deviation of quarterly UK housing returns are $1.58 \%$ and $2.38 \%$, respectively. However, there are big differences across regions. The mean return in London (L) appears to be the highest at $1.93 \%$ per quarter. 
Meanwhile, the average return in the South East (SE) region is $1.38 \%$, which is about twothirds of that in London. London also shows the highest Sharpe ratio; thus, residential properties in London have been the most attractive for household investment. On the contrary, Yorkshire and the Humber (YH) and North East (NE) show lower Sharpe ratios, 0.87 and 0.88, respectively. The first-order autocorrelation coefficient of housing returns in the entire UK is 0.79, which means that UK housing returns are persistent and predictable. The augmented Dickey-Fuller test shows that housing returns are stationary. Correlations between any two regions are generally greater than 0.6 , although SE has low correlations with the other regions.

Table 2 shows the basic statistical properties of the macroeconomic variables that we use to predict the core variables in this study. ${ }^{8}$ The augmented Dickey-Fuller test results show that all these variables are stationary except for the two interest rates (TB_3M and TB_10Y). ${ }^{9}$ As expected, housing returns are positively correlated with changes in consumption, GDP, industrial production, and sentiment (Blow, Hamilton and Leicester, 2009). However, they are not correlated with changes in labor income. Changes in labor income are positively correlated with interest rates (TB_3M, TB_10Y, and CRDT_SPRD), and interest rates are positively correlated with changes in GDP and CPI.

Note that the three variables to explain housing returns, consumption change (CNSUMPTN_R), stock return (FTSE_ALL_R), and change in human capital (GDHI_UK) in equation (9), are not correlated with each other: none of the correlation coefficients are significant at the $5 \%$ level. Therefore, our measure of overconfidence, which we developed in the previous section under the assumption that these three core explanatory variables are not

\footnotetext{
8 Data sources are the Office for National Statistics for gross domestic household income and CPI, OECD for the UK consumer confidence index and UK economic sentiment indicator, Bank of England for three-month Treasury bill rate and ten-year Treasury bond rate, and Data Stream for the other data.

9 During the sample period, UK interest rates have decreased, creating a downward trend. The first differentiated interest rate series, however, is not really useful in forecasting the three core explanatory variables.
} 
correlated, holds in the presence of the other core explanatory variables.

Table 3 summarizes the regression results for each of the core explanatory variables on the contemporaneous macroeconomic variables. We add the lagged consumption change and income change as explanatory variables because they are useful in forecasting due to their persistence. As expected, stock returns are the most difficult to predict; the adjusted R square value is lower than those of the other two. Stock returns appear to have significantly positive relationships with contemporaneous sentiment changes and unemployment rates, but they have a negative relationship with term spreads (Panel A), which is consistent with the findings of many studies, e.g., Brown and Cliff (2004), Boyd, Hu, and Jagannathan (2005), and Wang, Keswani, and Taylor (2006). As in previous studies that find a positive relationship between UK house prices and household consumption (Campbell and Cocco, 2007), housing returns appear to have significant relationships with contemporaneous consumption change (Panel B). Consumer confidence and GDP growth are also positively related to consumption changes. The pooled regression results in Panel $\mathrm{C}$ show that regional household incomes (per capita labor income change, GDHI) are not well explained by the macroeconomic variables: only stock returns and lagged GDHI have weak relationships with GDHI.

\section{III.2 Construction of Noisy Signals}

When households try to predict housing returns, they first need to forecast the three core explanatory variables, future consumption change, stock return, and human capital change. The signals used to forecast these core variables are noisy as they includes information about the future core variables as well as noise: $S_{\bullet t}=r_{\bullet t+1}+\varepsilon_{\bullet t}$ where $\varepsilon_{\bullet t} \sim N_{i . i . d .}\left(0, \sigma_{\bullet t}\right)$. Because we measure overconfidence by overprecision on the noisy signals, a critical issue in the empirical tests is how to identify the noisy signals households use to forecast the core variables. 
The noise should be part of the signal used to forecast the core variables without helping the forecast because it is noise.

We construct the noisy signals using the following four steps:

$$
\begin{aligned}
& 1^{\text {st }} \text { step: } f_{\bullet i k t}=\alpha_{\bullet i k}+\beta_{\bullet i k} r_{\bullet i t+1}+\epsilon_{\bullet i k t} . \\
& 2^{\text {nd }} \text { step: } f_{\bullet i k t}^{*}=\frac{f_{\bullet i k t}}{\beta_{\bullet i k}}-\frac{\alpha_{\bullet i k}}{\beta_{\bullet i k}}=r_{\bullet i t+1}+\frac{\epsilon_{\bullet i t}}{\beta_{\bullet i k}} . \\
& 3^{\text {rd }} \text { step: } r_{\bullet i t+1}=\mu_{\bullet i}+\sum_{k=1}^{K} \pi \pi_{\bullet i k} f_{\bullet i k t}^{*}+\epsilon_{\bullet i t+1} \text { to obtain } w_{\bullet i k t}^{*}=\frac{\pi_{\bullet i k}}{\sum_{k=1}^{K} \pi_{\bullet i k}} . \\
& 4^{\text {th }} \text { step: } S_{\bullet i t}=\sum_{k=1}^{K} w_{\bullet i k t}^{*} f_{\bullet i k t}^{*}=r_{\bullet i t+1}+\sum_{k=1}^{K} w_{\bullet i k t}^{*} \frac{\epsilon_{\bullet i t}}{\beta_{\bullet i k}} .
\end{aligned}
$$

Here, $f_{\bullet i k t}$ represents macroeconomic variable $k$ used to predict core variable $r_{\bullet i t}, i$ denotes the region, and $\epsilon_{\bullet i t} \sim N\left(0, \sigma_{r_{\bullet}}^{2}\right)$. The first two steps produce scaled macroeconomic variables, $f_{\bullet i k t}^{*} \mathrm{~s}$, that consist of $r_{\bullet i t+1}$, and noise $\left(\frac{\epsilon_{\bullet i t}}{\beta_{\bullet i k}}\right)$. The third and fourth steps are required to create a noisy signal when considering more than one macroeconomic variable: the weights on these macroeconomic variables are assumed to be proportional to the regression coefficients $\pi_{\bullet i k} \mathrm{~s}$. The error term in the $4^{\text {th }}$ step is regarded as the noise of the signal: $\varepsilon_{\bullet i t}=\sum_{k=1}^{K} w_{\bullet i k t}^{*} \frac{\epsilon_{\bullet i t}}{\beta_{\bullet i k}}$. The noise $\varepsilon_{\bullet i t}$ is thus part of the macroeconomic variables used to predict the core variables but is not correlated with the core variables, satisfying the conditions we set out above.

The regression results from the $3^{\text {rd }}$ step are reported in Table 4. As expected, when the noisy macroeconomic variables $\left(f_{\bullet i k t}^{*} \mathrm{~s}\right)$ are used to predict the core explanatory variables $\left(r_{\bullet i t+1}\right)$, they are not as useful as the realized contemporaneous macroeconomic variables in Table 3. When the $\mathrm{R}$ square values in Tables 3 and 4 are compared, the explanatory powers of the noisy macroeconomic variables decrease by $4-5 \%$ points for all three core explanatory variables. The results in Table 4 show that the main contributors to the prediction of the core explanatory variables are unemployment rate and credit spread for stock returns, consumer confidence and housing returns for consumption changes, and three-month Treasury Bill rate 
and stock returns for household income changes.

Figure 1 shows the core explanatory variables $\left(r_{\bullet i t+1}\right)$ and their corresponding noisy signals $\left(S_{\bullet i t}\right)$. The noisy signals are more volatile than the core explanatory variables: the standard deviations of stock market returns, consumption changes, and income changes are $8.2 \%, 0.8 \%$, and $2.8 \%$, respectively, whereas those of the noisy signals are $31.3 \%, 1.7 \%$, and $10.6 \%$, respectively. These differences in the volatilities of the noisy signals reflect the characteristics of the core variables. For example, consumption changes are more predictable than stock returns, and thus their signals have less noise than stock returns. When $S_{\bullet t}$ is used to predict $r_{\bullet t+1}$, the posterior expectation would appear as equation (11) in the absence of overconfidence. However, when households are overconfident about the signals, then their posterior expectation is biased, as in equation (12), by underestimating the variance of $\varepsilon_{\bullet i t}$. Next, we measure confidence biases using these noisy signals.

\section{III.3 Overconfidence in the core explanatory variables}

To measure overconfidence in equation (16), we first estimate the coefficients for noiseless and noisy signals on the observed returns, i.e., $\delta_{\bullet i t}$ and $\delta_{\bullet i t}^{\prime}$, in equations (17a) and (17b), respectively. Panel A in Table 5 reports the estimation results: stock returns and consumption changes have positive relationships with housing returns; $\delta_{\bullet i t}$ s for stock returns and consumption changes from the pooled regression are 0.286 and 0.098 , respectively, and those for individual regions are also all positive. As explained above, household income changes does not show any significant relationship with housing returns. Therefore, as suggested by the consumption-based asset pricing model, consumption and wealth explain housing returns.

The coefficients for noisy signals in equation (17b) are expected to have the same sign 
as the $\delta_{\text {.it }}$ s because under- or over-confidence should change only the magnitude of the coefficients, not their signs. ${ }^{10}$ The results in panel A show that the signs do not change in the pooled regressions. The coefficients are $0.01,0.307$, and -0.559 for stock returns and changes in consumption and human capital, respectively. However, the coefficients are not significant or show different signs in various regions for stock returns and household income changes, suggesting that regional housing returns are difficult to predict using these core variables. On the other hand, consumption changes have significant relationships with housing returns, and the coefficients for noisy signals are larger than those for noiseless signals, indicating overconfidence.

Using the estimates in panel A, we estimate overconfidence $\left(\rho_{\bullet i t}\right)$ by multiplying the variance of the signal to $1-\delta_{\bullet i t} / \delta_{\bullet i t}^{\prime}$, as in equation (16). A positive (negative) value of this overconfidence measure indicates that households are overconfident (underconfident) about the signals. When the signs of $\delta_{\bullet i t}$ and $\delta_{\bullet i t}^{\prime}$ are not the same or when $\delta_{\bullet i t}^{\prime}$ is close to zero such that $\delta_{\bullet i t} / \delta_{\bullet i t}^{\prime}$ is negative or too large, we do not conclude that household overconfidence exists. Panel B also reports $t$ statistics for the null hypothesis $H_{0}: \delta_{\bullet i t}=\delta_{\bullet i t}^{\prime}$.

The results show that the null hypothesis is rejected for consumption changes and household income changes, and thus households respond irrationally to those two core explanatory variables when they predict housing returns. Therefore, as the pooled regression results in panel A suggest, when households predict their consumption to increase, they tend to overreact to the signal and predict house prices to increase more than what the consumption signal suggests. On the contrary, when households predict an increase in their income, they

\footnotetext{
${ }^{10}$ When the signs of $\delta_{\bullet i t}$ and $\delta_{\bullet i t}^{\prime}$ are not the same, households interpret the signals in the opposite way, i.e., contrarian to signals. As over- or under-confidence represents under- or over-estimation of the volatility in noise and thus does not affect the covariance between housing returns and signals, contrarian behavior is different from what we investigate in this study, i.e., overconfidence. In several cases, stock returns and household income changes show different signs for $\delta_{\bullet i t}$ and $\delta_{\bullet i t}^{\prime}$ but most of the estimates are not significantly different from zero.
} 
overreact to the signal and believe that house prices will decrease further than what the household income really indicates. However, households are not overconfident in the signal about stock returns, although stock returns do affect housing returns (panel A).

Some interesting regional differences appear in panel B. Households appear to be overconfident about the signal of stock returns in East Midlands, London, the East, and the South West, although it is not statistically significant. Households in those areas are also overconfident about the signals of their income changes. On the other hand, households in all regions are overconfident about the signal of consumption changes. Households in three regions (East Midlands, London, East) are overconfidence in the noisy signals of all three core explanatory variables.

\section{III.4 The Effects of Overconfidence on Housing Returns}

The results of individual explanatory variables in Table 5 do not directly show how much housing returns are affected by overconfidence in the presence of other variables. To answer that question, we first estimate how much the coefficients are biased by overconfidence using equation (13), and then we report the coefficients whose overconfidence biases are corrected.

The results in panel A of Table 6 show that the coefficients on the noisy signals of consumption changes are all biased upward. On average, coefficients on the noisy signals are twice as large as they should be, ranging from $111 \%$ in the East to $404 \%$ in the North East. Coefficients on the noisy signals of household income changes are on average ten times as large as they should be, but those exceptional biases are caused by the small coefficients on the noiseless signals, which are not different from zero. The coefficients on the noisy signals of stock returns appear to be biased downward, but those biases are not statistically significant, 
as in Table 5.

In panel $\mathrm{B}$ of Table 6 , we estimate the biased coefficients using the following regression of housing returns, as in equation (14):

$$
r_{i t+1}^{*}-r_{f t+1}=\gamma_{i 0 t}+\gamma_{i c t} S_{c t}^{\prime}+\gamma_{i s t} S_{s t}^{\prime}+\gamma_{i h t} S_{h t}^{\prime}+\varphi\left(r_{i t}^{*}-r_{f t}\right)+e_{i t+1},
$$

where $\varphi$ explains persistence in housing returns. Similar to our previous results, the noisy signals for stock returns are not really useful except in a few regions, such as the North East and South East, whose housing returns are negatively predicted by the signals. A strong prediction power comes from the noisy signals for consumption changes and household income changes, which positively and negatively predict housing returns, respectively. These results are robust in the presence of lagged housing returns. On average, these three noisy signals predict $40 \%$ of housing returns. They show the lowest prediction power in the North East $(21.5 \%)$ and the highest in the South West (59.2\%).

The unbiased (overconfidence-free) coefficients in panel $\mathrm{C}$ are estimated by correcting the coefficients in panel B using the bias ratios in panel A. The corrected coefficients on the noisy signals for consumption changes are smaller than the coefficients reported in panel B, whereas those for household income changes are larger than the coefficients in panel B. The coefficients in panels B and C of Table 6 are then used to calculate two housing returns, i.e., returns expected by households who are overconfident in their noisy signals for the three core explanatory variables and the returns expected by rational households without overconfidence biases. The results are summarized in Figure 2 and Table 7 together with realized housing returns.

The results show that the realized housing returns are affected by household overconfidence. The average realized housing returns in panel A of Table 7 are similar to the expected returns affected by overconfidence in panel $\mathrm{C}$ rather than the overconfidence-bias- 
corrected returns in panel B. For example, the correlation coefficients between the realized returns and overconfidence affected expected returns are approximately 0.5 , whereas those between the realized returns and overconfidence-free expected returns are approximately 0.2 .

Figure 2 shows that UK households under-responded to the macroeconomic variables in the early 1980s and 1990s and during the 2008 financial crisis. They were overconfident for more than ten years from 1994 to 2007 and have been again since the recovery from the financial crisis. For example, the average return difference in the UK between overconfidencebiased and -corrected expected returns is $-0.22 \%$ per quarter in the $1990 \mathrm{~s}$, but becomes $0.54 \%$ per quarter in the 2000s. In the 2010s the effects of overconfidence on housing returns have increased further to $0.7 \%$ per quarter. Figure 3 shows that the overconfidence-bias-free cumulative returns have trended slightly downward since the financial crisis, whereas the posterior expected return affected by household overconfidence has tended to increase during the most recent period.

It is interesting that overconfidence-driven house price increases continue in London in the 2010s. In fact, London leads the other regions; overconfidence contributes approximately $1.3 \%$ per quarter during this period. London also shows a distinct pattern in overconfidence in the past. In the 1980s and 1990s, households in London were under-confident: overconfidencebiased expected returns are $0.44 \%$ per quarter less than what the core explanatory variables suggest. In the 2000s and 2010s, London house prices have increased beyond what the macroeconomic variables suggest. In general, household expectations in the northern areas (NE, $\mathrm{NW}, \mathrm{YH}$ ) were relatively more overconfident than in the southern areas (L, SE, SW) in the 1980s and 1990s, and that trend has reversed in the 2010s. 


\section{Concluding Remarks}

One of the most common behavioral biases discussed in the asset pricing literature is overconfidence. Despite the wide-spread evidence of overconfidence (De Long et al., 1991; Griffin and Tversky, 1992; Odean, 1998), the effects of overconfidence by households on housing markets have not been investigated. We have proposed a consumption-based equilibrium asset pricing model that identifies three core explanatory variables for residential property returns: changes in consumption, stock returns, and changes in human capital. When overconfident households try to predict housing returns, they would give much more weights on the signals of these variables during their Bayesian updating process.

Using residential property return data from nine UK regions together with other macroeconomic variables, we find that UK households are overconfident in the noisy signals for consumption growth and human capital growth. They have been overconfident in London and other southern regions since the mid-1990s. During the 1980s and 1990s, households in northern regions were relatively more overconfident. We show evidence that the recent price increase in the UK housing market is driven by household overconfidence. 


\section{References}

Aron, j., J. Muellbauer, and A. Murphyi, 2006, Housing Wealth and UK Consumption, Economic Outlook 30(4):11-20.

Attanasio, O.P., L. Blow, R. Hamilton, and A. Leicester, 2009, Booms and Busts: Consumption, House Prices and Expectations, Economica 76(301):20-50.

Baker M.P, J. Wurgler, 2006, Investor sentiment and the cross-section of stock returns. Journal of Finance 61(4):1645-1680.

Bansal, R., D. Kiku, I. Shaliastovich, and A. Yaron, 2014, Volatility, the Macroeconomy, and Asset Prices, Journal of Finance 69(6):2471-2511.

Barberis N., A. Shleifer, and R. Vishny, 1998, A model of investor sentiment, Journal of Financial Economics 49(3):307-343.

Boyd, J.H., J. Hu, and R. Jagannathan, 2005, The Stock Market's Reaction to Unemployment News: Why Bad News Is Usually Good for Stocks, Journal of Finance 60(2):649-672.

Breeden, D.T., 1979, An Intertemporal Asset Pricing Model with Stochastic Consumption and Investment Opportunities, Journal of Financial Economics Sep. 7: 265-296.

Brown, G.W., and M.T. Cliff, 2004, Investor Sentiment and the Near-Term Stock Market, Journal of Empirical Finance 11(1): 1-27.

Brunnermeier, M.K. and C. Julliard, 2008, Money Illusion and Housing Frenzies, The Review of Financial Studies 21(1):135-180.

Bucchianeri, G.W., 2011, The Anatomy of a Housing Bubble: Overconfidence, Media and Politics, Working Paper.

Campbell, J.Y. and J.F. Cocco, 2007, How do house prices affect consumption? Evidence from micro data, Journal of Monetary Economics 54:591-621.

Campbell, J.Y. and T.O. Vuolteenaho, 2004, Bad Beta, Good Beta, American Economic Review 94:1249-1275.

Campbell, J.Y., 1996, Understanding Risk and Return, Journal of Political Economy 104: 298345.

Caporale, G.M. and R.M. Sousa, 2015, Consumption, Wealth, Stock and Housing Returns: Evidence from Emerging Markets, Research in International Business and Finance forthcoming.

Caporale, G.M., R.M. Sousa, and M.E. Wohar, 2016, Can the Consumption-Wealth Ratio Predict Housing Returns? Evidence from OECD Countries, Forthcoming.

Case, K.E. and R.J. Shiller, 2003, Is There a Bubble in the Housing Market?, Brookings Papers on Economic Activity 34(2):299-362.

Case, K.E., J.M. Quigley, and R.J. Shiller, 2005, Comparing Wealth Effects: The Stock Market Versus The Housing Market, Advances in Macroeconomics 5(1):1-32.

Case, K.E., J.M. Quigley, and R.J. Shiller, 2012, Wealth Effects Revisited 1975-2012, Critical Finance Review 2012(2):101-128.

Chen, N., R. Roll, and S.A. Ross, 1986, Economic Forces and the Stock Market, Journal of Business 59(3):383-403.

Cho, Y., S. Hwang, and J. Shin, 2015, Does Illiquidity Matter in Residential Properties?, 
Working Paper.

Chuang, W.I. and B.S. Lee, 2006, An empirical evaluation of the overconfidence hypothesis, Journal of Banking and Finance 30:2489-2515.

Daniel K., D. Hirshleifer, and A. Subrahmanyam, 1998, Investor psychology and security market under- and overreactions, Journal of Finance 53(6):1839-1885.

Daniel K., D. Hirshleifer, and A. Subrahmanyam, 2001, Overconfidence, Arbitrage, and Equilibrium Asset Pricing, Journal of Finance 56(3):921-965.

De Giorgi, G. and L. Gambetti, 2015, Business cycle fluctuations and the distribution of consumption, Staff Reports 716, Federal Reserve Bank of New York.

Di Giovanni, J. and A. Matsumoto, 2011, The value of human capital wealth, Global COE HiStat Discussion Paper Series 174.

Engel, C. and J.H. Rogers, 2009, Expected Consumption Growth from Cross-Country Surveys: Implications for Assessing International Capital Markets, IMF Staff Papers, Palgrave Macmillan 56(3):543-573.

Epstein, L. and M. Schneider, 2008, Ambiguity, Information Quality, and Asset Pricing, Journal of Finance 63(1):197-228.

Epstein, L. and S.E. Zin, 1989, Substitution, Risk Aversion, and the Temporal Behavior of Consumption and Asset Returns: a Theoretical Framework, Econometrica 57,937-969.

Epstein, L. and S.E. Zin, 1991, Substitution, Risk Aversion, and the Temporal Behavior of Consumption and Asset Returns: an Empirical Analysis, Journal of Political Economy 99:263-286.

Escobari, D., D. Damianov, and A. Bello, 2012, A Time Series Test to Identify Housing Bubbles, Journal of Economics and Finance 39(1):136-152.

Fama, E.F. and K.R. French, 2001, Disappearing dividends: changing firm characteristics or lower propensity to pay?, Journal of Financial Economics 60:3-43.

Flavin, M. and S. Nakagawa, 2008, A Model of Housing in the Presence of Adjustment Costs: A Structural Interpretation of Habit Persistence, American Economic Review 98(1): 474-495.

Gervais, S. and T. Odean, 2001, Learning to be overconfident, Review of Financial Studies 14(1):1-27.

Glaeser, E.L., J. Gyourko, and A. Saiz, 2008, Housing Supply and Housing Bubbles, Journal of Urban Economics 64(2):198-217.

Goodheart, C. and B. Hofmann, 2008, House prices, money, credit, and the macroeconomy, Oxford Review of Economic Policy 24(1):180-205.

Griffin, D. and A. Tversky, 1992, The weighing of evidence and the determinants of confidence, Cognitive Psychology 24:411-435.

Hall, R.E. and F.S. Mishkin, 1982, The Sensitivity of Consumption to Transitory Income Estimates from Panel Data on Households, Econometrica 50:461-481.

Hansen, L.P. and K.J. Singleton, 1983, Stochastic consumption, risk aversion, and the temporal behavior of asset returns, Journal of Political Economy 91:249-268.

Harvey, F., 1993, The Risk and Predictability of International Equity Returns, Review of Financial Studies 6(3):527-566. 
Helbling, T. and M.E. Terrones, 2003, Real and Financial Effects of Bursting Asset Price Bubbles, IMF World Economic Outlook April 2003:61-94.

Hirshleifer, D., A. Subrahmanyam, and S. Titman, 2006,Feedback and the Success of Irrational Investors, Journal of Financial Economics 81(2):311-338.

Hong, H and J.C. Stein, 1999, A unified theory of underreaction, momentum trading, and overreaction in asset markets, Journal of Finance 54(6):2143- 2184.

Hott, C., 2012, The Influence of Herding Behavior on House Prices, Journal of European Real Estate Research 5(3):177-198.

Hwang, M. and J.M. Quigley, 2006, Economic Fundamentals in Local Housing Markets: Evidence from U.S. Metropolitan Regions, Journal of Regioanl Science 46(3):425-453.

Hwang, S., 2015, Overconfidence in Cross-sectional Asset Returns, Conference on AsiaPacific Financial Markets 2015 Paper.

Iacoviello, M., 2005, House Prices, Borrowing Constraints, and Monetary Policy in the Business Cycle, American Economic Review 95(3):739-764.

Jagnnathan, R. and Z. Wang, 1996, The Conditional CAPM and the Cross-Section of Expected Returns, Journal of Finance 51(1):3-53.

Kallberg, J.C., C.H. Liu, and P. Pasquariello, 2014, On the price comovement of U.S. residential real estate markets, Real Estate Economics 42(1):71-108.

Kelly, B. and S. Pruitt, 2013, Market Expectations in the Cross-Section of Present Values, Journal of Finance 68(5):1721-1756.

Kivedal, B.K., 2013, Testing for Rational Bubbles in the US Housing Market, Journal of Macroeconomics 38(B):369-381.

Kiyotaki, N. and J. Moore, 2005, Credit Cycles, Journal of Political Economy 105(2):211-248.

Lettau, M. and S. Ludvigson, 2001, Consumption, Aggregate Wealth and Expected Stock Returns, Journal of Finance 56:815-849.

Lintner, J., 1965, The Valuation of Risk Assets and the Selection of Risky Investments in Stock Portfolios and Capital Budgets, Review of Economics and Statistics 47:13-37.

Lustig, H. and S. Van Nieuwerburgh, 2008, The Returns on Human Capital: Good News on Wall Street is Bad News on Main Street, Review of Financial Studies 21(5):2097-2137.

Mayers, D., 1972, Nonmarketable assets and capital market equilibrium under uncertainty, in Michael C. Jensen, Ed.: Studies in the Theory of Capital Markets (Praeger, New York), pp.223-248.

Merkle, C., 2013, Financial Overconfidence Over Time - Foresight, Hindsight, and Insight of Investors, AFA 2013 San Diego Meetings Paper.

Miller, E., 1977, Risk Uncertainty and Divergence of Opinion, Journal of Finance 32(4):11511168.

Moore, D.A. and P.J. Healy, 2008, The Trouble with Overconfidence, Psychological Review 115(2):502-517.

Mossin, J., 1966, Equilibrium in a Capital Asset Market, Econometrica 35:768-783.

Odean, T., 1998, Are investors reluctant to realize their losses?, Journal of Finance 53(5):17751798.

Ofek, E. and M. Richardson, 2003, DotCom Mania: The Rise and fall of internet stock prices, 
Journal of Finance 58(3):1113-1137.

Pavlov, P. and S. Wachter, 2011, Subprime Lending and Real Estate Prices, Real Estate Economics 39(1):1-17.

Piazzesi, M., M. Schneider, and S. Tuzel, 2007, Housing, Consumption, and Asset Pricing, Journal of Financial Economics 83:531-569.

Polk, C., S. Thompson and T. Vuolteenaho, Cross-Sectional Forecasts Of The Equity Premium, Journal of Financial Economics 81(1):101-147.

Scheinkman J.A. and W. Xiong, 2003, Overconfidence and speculative bubbles, Journal of Political Economy 111(6):1183-1219.

Scheinkman, J. and W. Xiong, 2003, Overconfidence and Speculative Bubbles, Journal of Political Economy 111(6):1183-1219.

Sharpe, W.F., 1964, Capital Asset Prices: A Theory of Market Equilibrium Under Conditions of Risk, Journal of Finance 19: 425-42.

Shiller, R.J., 2005, Irrational Exuberance, Princeton University Press.

Slacalek, J., 2009, What Drives Personal Consumption? The Role of Housing and Financial Wealth, ECB Working Paper No.1117.

Stambaugh, R.F., 1982, On the exclusion of assets from tests of the two-parameter model: A sensitivity analysis, Journal of Financial Economics 10:237-268.

Statman, M., S. Thorley, and K. Vorkink, 2006, Investor overconfidence and trading volume, Review of Financial Studies 19(4):1531-1565.

Wang, Y.H., A. Keswani, and S.J. Taylor, 2006, The relationships between sentiment, returns and volatility, International Journal of Forecasting 22(1):109-123. 


\section{Table 1. Statistical properties of residential property returns}

This table shows the basic statistical properties of housing returns (in percentage) calculated by the Nationwide House Price Index, which provides quarterly indices for nine UK regions, i.e., specifically, East (E), East Mids (EM), London (L), North East (NE), North West (NW), South East (SE), South West (SW), West Mids (WM), Yorks and Hside (YH), as well as the nation-wide index (UK). The sample period is from 1980 to 2014.

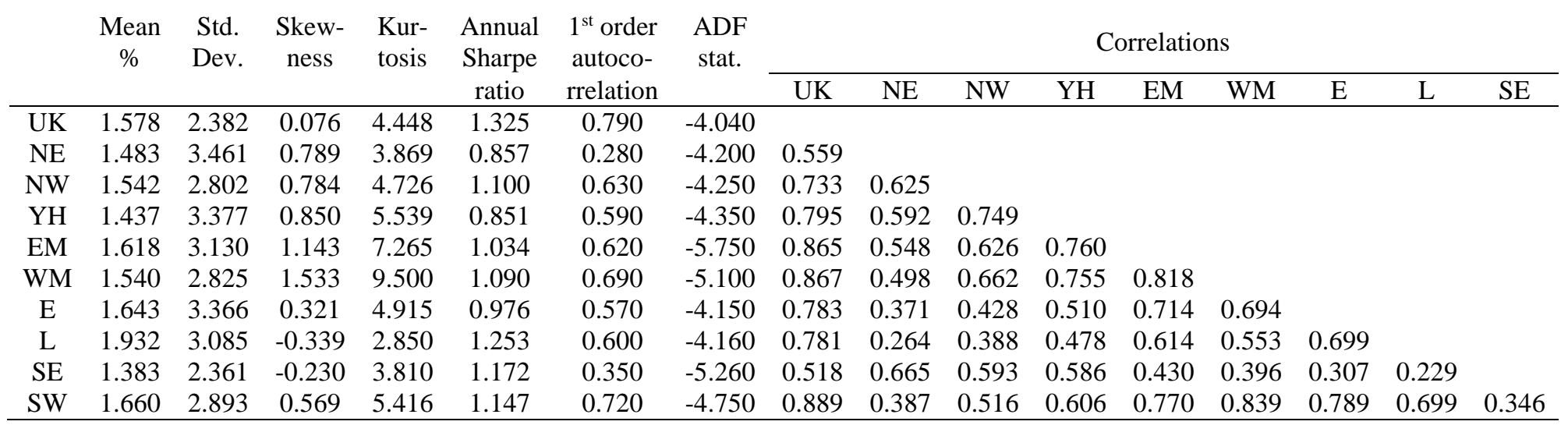




\section{Table 2. Statistical properties of the macroeconomic variables}

This table shows the basic statistical properties of the macroeconomic variables which are quarterly basis from 1980 to 2014 . R_UK represents the residential property returns in the whole United Kingdom. FTSE_ALL_R means the returns of FTSE All Share index. CNSUMPTN_R and GDHI_UK represent changes in household consumption and changes in gross disposable household income, respectively. GDP_R, CPI_R, and PRDCTN_A_R mean GDP growth rates, changes in Customer Price Index, and changes in Industrial Production of all industries, respectively. CNFDNC and SNTMNT_R represent UK consumer good confidence indicator and changes in UK economic sentiment indicator, respectively. CRDT_SPRD and TERM_SPRD mean the yield spreads between Moody's Aaa corporate bond and Baa corporate bond and the yield spreads between three month and ten year UK Government bonds. TB_3M and TB_10Y represent annual yields of three-month Treasury Bill and ten- year UK Government bond, respectively.

\begin{tabular}{|c|c|c|c|c|c|c|c|c|c|c|c|c|c|c|c|c|c|c|}
\hline & \multirow[b]{2}{*}{ Mean } & \multirow[b]{2}{*}{$\begin{array}{l}\text { Std. } \\
\text { Dev. }\end{array}$} & \multirow[b]{2}{*}{$\begin{array}{c}\text { Skewne } \\
\text { ss }\end{array}$} & \multirow[b]{2}{*}{$\begin{array}{c}\text { Kurtosi } \\
\text { s }\end{array}$} & \multirow[b]{2}{*}{$\begin{array}{c}1^{\text {st }} \text { order } \\
\text { autocorre } \\
\text { lation }\end{array}$} & \multirow[b]{2}{*}{$\begin{array}{l}\text { ADF } \\
\text { stat. }\end{array}$} & \multicolumn{12}{|c|}{ Correlations } \\
\hline & & & & & & & R_UK & $\begin{array}{c}\text { FTSE } \\
\text { ALL } \\
\text { _R } \\
\end{array}$ & $\begin{array}{c}\text { CNSU } \\
\text { MPTN } \\
\quad \mathrm{R} \\
\end{array}$ & $\begin{array}{c}\text { GDHI } \\
\text { _UK }\end{array}$ & GDP_R & CPI_R & $\begin{array}{l}\text { PRDCT } \\
\text { N_A_R }\end{array}$ & $\begin{array}{c}\text { CNFD } \\
\text { NC }\end{array}$ & $\begin{array}{l}\text { SNTM } \\
\text { NT_R }\end{array}$ & $\begin{array}{c}\text { CRD } \\
\text { T_SP } \\
\text { RD }\end{array}$ & $\begin{array}{c}\text { TER } \\
\text { M_SP } \\
\text { RD }\end{array}$ & $\mathrm{TB}_{\mathrm{M}}{ }^{3}$ \\
\hline R_UK & 1.578 & 2.382 & 0.076 & 4.448 & 0.789 & -4.043 & & & & & & & & & & & & \\
\hline FTSE_ALL_R & 3.308 & 8.166 & -0.676 & 4.142 & 0.016 & -11.53 & 0.142 & & & & & & & & & & & \\
\hline CNSUMPTN_R & 0.689 & 0.848 & -0.525 & 4.213 & 0.275 & -3.889 & 0.491 & 0.103 & & & & & & & & & & \\
\hline GDHI_UK & 1.431 & 2.838 & 0.715 & 39.608 & 0.289 & -10.81 & -0.084 & -0.133 & -0.028 & & & & & & & & & \\
\hline GDP_R & 1.416 & 1.044 & 0.010 & 3.729 & 0.431 & -4.556 & 0.381 & 0.202 & 0.291 & 0.181 & & & & & & & & \\
\hline CPI_R & 0.916 & 1.015 & 2.120 & 9.170 & 0.290 & -3.151 & -0.113 & 0.085 & -0.261 & 0.057 & 0.318 & & & & & & & \\
\hline PRDCTN_A_R & 0.096 & 1.270 & -0.821 & 5.830 & 0.415 & -7.579 & 0.264 & 0.093 & 0.413 & -0.130 & 0.353 & -0.096 & & & & & & \\
\hline CNFDNC & 1.000 & 0.014 & -0.276 & 2.008 & 0.896 & -3.935 & 0.616 & 0.071 & 0.435 & -0.128 & 0.113 & -0.349 & 0.292 & & & & & \\
\hline SNTMNT_R & 0.138 & 4.639 & 0.085 & 4.074 & 0.389 & -7.755 & 0.312 & 0.215 & 0.216 & -0.363 & 0.115 & -0.010 & 0.266 & 0.269 & & & & \\
\hline CRDT_SPRD & 1.106 & 0.478 & 1.679 & 6.183 & 0.876 & -3.790 & -0.119 & 0.053 & -0.307 & 0.293 & 0.044 & 0.315 & -0.329 & -0.398 & -0.164 & & & \\
\hline TERM_SPRD & 0.538 & 1.754 & -0.381 & 2.722 & 0.869 & -3.207 & 0.003 & -0.051 & -0.034 & -0.146 & -0.238 & -0.203 & 0.116 & 0.038 & 0.344 & 0.044 & & \\
\hline TB_3M & 6.609 & 4.242 & 0.263 & 2.243 & 0.958 & -1.924 & 0.006 & 0.135 & 0.070 & 0.222 & 0.557 & 0.524 & 0.043 & -0.197 & -0.182 & 0.256 & -0.642 & \\
\hline TB_10Y & 7.147 & 3.395 & 0.360 & 2.092 & 0.964 & -1.309 & 0.009 & 0.142 & 0.070 & 0.203 & 0.573 & 0.549 & 0.114 & -0.227 & -0.050 & 0.343 & -0.285 & 0.918 \\
\hline
\end{tabular}




\section{Table 3. Regression results for the three core explanatory variables}

This table presents the regression results of the three core variables $\left(r_{\bullet i t+1}\right)$, i.e., FTSE_ALL_R (FTSE All-share index returns), CNSUMPTN_R (consumption changes), and GDHI_* (regional gross disposable household income changes) on the contemporaneous explanatory variables.

$$
r_{\bullet i t+1}=\mu_{\bullet i}+\sum_{k=1}^{K} \pi_{\bullet i k} f_{\bullet i k t+1}+\epsilon_{\bullet i t+1},
$$

where $f_{\bullet i k t+1} \mathrm{~s}$ are explanatory variables: CPI_R (Customer Price Index changes), PRDCTN_A_R (Industrial production changes - All industries), SNTMNT_R (UK economic sentiment indicator changes), TB_10Y (ten year UK Government bond yield), CRDT_SPRD (yield spread between Moody's Aaa corporate bond and Baa corporate bond), TERM_SPRD (yield spread between three month and ten year UK Government bonds), UMP (unemployment rate), GDHI_UK (UK household income changes), R_UK (UK housing market returns), CNFDNC_R/1000 (UK consumer good confidence indicator), GDP_R (GDP growth rate), R_* (regional housing market returns), and TB_3M (three-month Treasury Bill rates). * means individual UK regions. Consumption changes and household income changes appear not to have seasonality. The numbers in parentheses are t-statistics using White cross-section standard errors and covariance matrix.

\section{A. Regression of FTSE index returns (FTSE_ALL_R)}

\begin{tabular}{ccc} 
Explanatory variables & Coefficients & Std. Error \\
\hline C & -0.007 & $(0.018)$ \\
CPI_R & 0.451 & $(0.749)$ \\
PRDCTN_A_R & 0.031 & $(0.565)$ \\
SNTMNT_R & 0.460 & $(0.165)$ \\
TB_10Y & -0.483 & $(0.428)$ \\
CRDT_SPRD & 1.635 & $(1.382)$ \\
TERM_SPRD & -1.060 & $(0.452)$ \\
UMP & 0.971 & $(0.431)$ \\
\hline Adjusted R-squared & $11.31 \%$ & \\
Durbin-Watson stat & 2.160 & \\
\hline
\end{tabular}

\section{B. Regression of consumption changes (CNSUMPTN_R)}

\begin{tabular}{ccc} 
Explanatory variables & Coefficients & Std. Error \\
\hline C & -0.153 & $(0.076)$ \\
GDHI_UK & 0.000 & $(0.009)$ \\
R_UK & 0.094 & $(0.035)$ \\
FTSE_ALL_R & 0.002 & $(0.008)$ \\
CNFDNC & 0.157 & $(0.076)$ \\
GDP_R & 0.113 & $(0.064)$ \\
CNSUMPTN_R(-1) & 0.027 & $(0.091)$ \\
\hline Adjusted R-squared & $28.58 \%$ & \\
Durbin-Watson stat & 1.860 & \\
\hline
\end{tabular}

\section{Pooled regression of regional gross disposable household income changes (GDHI_*)}

\begin{tabular}{ccc} 
Explanatory variables & Coefficients & Std. Error \\
\hline C & 0.004 & $(0.006)$ \\
FTSE_ALL_R & -0.054 & $(0.040)$ \\
R_* & -0.056 & $(0.089)$ \\
TB_3M & 0.107 & $(0.139)$ \\
TB_10Y & 0.021 & $(0.114)$ \\
GDHI_*(-1) & 0.255 & $(0.183)$ \\
\hline Adjusted R-squared & $12.13 \%$ & \\
Durbin-Watson stat & 1.840 & \\
\hline
\end{tabular}


Table 4. Regression results for the signals of the three core explanatory variables

This table presents the regression results of the three core variables $\left(r_{\bullet i t+1}\right)$, i.e., FTSE_ALL_R (FTSE All-share index returns), CNSUMPTN_R (consumption changes), and GDHI** (regional gross disposable household income changes) on the scaled macroeconomic variables $f_{\bullet i k t}^{*} \mathrm{~s}$ :

$$
r_{\bullet i t+1}=\mu_{\bullet i}+\sum_{k=1}^{K} \pi_{\bullet i k} f_{\bullet i k t}^{*}+\epsilon_{\bullet i t+1}
$$

where $r_{\bullet i t+1}$ represents the core explanatory variable, $f_{\bullet i k t}^{*} \mathrm{~s}$ are scaled macroeconomic variables $\left(f_{\bullet i k t}^{*}=\frac{f_{\bullet i k t}}{\beta_{\bullet i k}}-\frac{\alpha_{\bullet i k}}{\beta_{\bullet i k}}\right.$ from $\left.f_{\bullet i k t}=\alpha_{\bullet i k}+\beta_{\bullet i k} r_{\bullet i t+1}+\epsilon_{\bullet i k t}\right)$, and $i$ represents a region. $w^{*} \mathrm{~s}$ are weights calculated with the regression coefficients $\left(w_{\bullet i k}^{*}=\frac{\pi_{\bullet i k}}{\sum_{k=1}^{K} \pi_{\bullet i k}}\right)$.

\section{A. Regression of FTSE index returns (FTSE_ALL_R)}

\begin{tabular}{cccc} 
Explanatory variables & Coefficients & Std. Error & $w^{*}$ \\
\hline C & 0.030 & $(0.007)$ & \\
CPI_R & -0.001 & $(0.002)$ & -0.022 \\
PRDCTN_A_R & 0.005 & $(0.004)$ & 0.066 \\
SNTMNT_R & 0.000 & $(0.001)$ & -0.002 \\
TB_10Y & 0.005 & $(0.026)$ & 0.069 \\
CRDT_SPRD & 0.010 & $(0.016)$ & 0.145 \\
TERM_SPRD & 0.000 & $(0.000)$ & -0.002 \\
UMP & 0.051 & $(0.030)$ & 0.745 \\
\hline Adjusted R-squared & $6.34 \%$ & & \\
Durbin-Watson stat & 2.104 & & \\
\hline
\end{tabular}

\section{B. Regression of consumption changes (CNSUMPTN_R)}

\begin{tabular}{cccc} 
Explanatory variables & Coefficients & Std. Error & $w^{*}$ \\
\hline C & 0.005 & $(0.001)$ & \\
GDHI_UK & 0.000 & $(0.000)$ & 0.001 \\
R_UK & 0.073 & $(0.046)$ & 0.295 \\
FTSE_ALL_R & 0.027 & $(0.017)$ & 0.110 \\
CNFDNC & 0.142 & $(0.050)$ & 0.571 \\
GDP_R & 0.006 & $(0.019)$ & 0.024 \\
\hline Adjusted R-squared & $24.53 \%$ & & \\
Durbin-Watson stat & 1.734 & & \\
\hline
\end{tabular}

C. Pooled regression of regional gross disposable household income changes (GDHI**)

\begin{tabular}{cccc} 
Explanatory variables & Coefficients & Std. Error & $w^{*}$ \\
\hline C & 0.013 & $(0.002)$ & \\
FTSE_ALL_R & 0.030 & $(0.018)$ & 0.359 \\
R_? & 0.002 & $(0.004)$ & 0.024 \\
TB_3M & 0.058 & $(0.035)$ & 0.701 \\
TB_10Y & -0.007 & $(0.022)$ & -0.083 \\
\hline Adjusted R-squared & $8.01 \%$ & & \\
Durbin-Watson stat & 1.589 & & \\
\hline
\end{tabular}




\section{Table 5. Overconfidence in the core explanatory variables}

Panel A shows the regression results of the noiseless signals and noisy signals on the property returns in equations (17a) and (17b),

$$
\begin{gathered}
r_{\bullet t+1}=\mu_{\bullet}^{\prime}+\delta_{i \bullet t} r_{i t+1}^{*}+e_{\bullet t+1}^{\prime} \\
S_{\bullet t}^{\prime}=\mu_{\bullet}^{\prime}+\delta_{i \bullet t}^{\prime} r_{i t+1}^{*}+e_{\bullet t+1}^{\prime},
\end{gathered}
$$

where $S_{\bullet t}^{\prime}, r_{\bullet t+1}$, and $r_{i t+1}^{*}$ are the noisy signal, the realized signal, and a property return, respectively. In panel A, we use a common constant because fixed cross-section effects appear not to be significant the pooled regressions. Panel B reports the ratios of deltas $\left(\frac{\delta_{\mathbf{i} \bullet t}}{\delta_{\mathbf{i} \bullet t}^{\prime}}\right)$, the t statistics for $\delta_{\bullet i t}-\delta_{\bullet i t}^{\prime}$, and overconfidence biases $\left(\rho_{\mathbf{i} \bullet t}=\right.$ $\left.\operatorname{Var}_{\mathrm{t}}\left(\mathrm{S}_{\bullet \mathrm{t}}^{\prime}\right)\left(1-\frac{\delta_{\mathrm{i} \bullet \mathrm{t}}}{\delta_{\mathrm{i} \cdot \mathrm{t}}^{\prime}}\right)\right)$ in each regions. White cross-section standard errors are reported in the brackets.

\begin{tabular}{|c|c|c|c|c|c|c|c|c|c|c|c|c|}
\hline \multirow[b]{3}{*}{ Pooled } & \multicolumn{4}{|c|}{ Stock market returns } & \multicolumn{4}{|c|}{ Consumption changes } & \multicolumn{4}{|c|}{ Household income changes } \\
\hline & \multicolumn{2}{|c|}{$r_{\bullet i t+1}($ Equation 17a) } & \multicolumn{2}{|c|}{$S_{\bullet i t+1}^{\prime}($ Equation 17b) } & \multicolumn{2}{|c|}{$r_{\bullet i t+1}($ Equation 17a) } & \multicolumn{2}{|c|}{$S_{\bullet i t+1}^{\prime}($ Equation $17 \mathrm{~b})$} & \multicolumn{2}{|c|}{$r_{\bullet i t+1}($ Equation 17a) } & \multicolumn{2}{|c|}{$S_{\bullet i t+1}^{\prime}($ Equation 17b) } \\
\hline & 0.286 & $(0.223)$ & 0.010 & $(0.607)$ & 0.098 & $(0.017)$ & 0.307 & $(0.030)$ & -0.045 & $(0.098)$ & -0.559 & $(0.220)$ \\
\hline UK & 0.488 & $(0.358)$ & -0.035 & $(0.978)$ & 0.175 & $(0.023)$ & 0.523 & $(0.046)$ & -0.101 & $(0.154)$ & -1.158 & $(0.375)$ \\
\hline NE & 0.109 & $(0.242)$ & -0.766 & $(0.64)$ & 0.042 & $(0.018)$ & 0.214 & $(0.036)$ & -0.036 & $(0.081)$ & -0.129 & $(0.220)$ \\
\hline NW & 0.408 & $(0.272)$ & -0.714 & $(0.764)$ & 0.102 & $(0.028)$ & 0.342 & $(0.044)$ & 0.076 & $(0.042)$ & -0.177 & $(0.286)$ \\
\hline $\mathrm{YH}$ & 0.439 & $(0.247)$ & -0.105 & $(0.633)$ & 0.059 & $(0.022)$ & 0.278 & $(0.032)$ & 0.053 & $(0.035)$ & -0.485 & $(0.308)$ \\
\hline EM & 0.184 & $(0.257)$ & 0.204 & $(0.645)$ & 0.106 & $(0.02)$ & 0.332 & $(0.041)$ & -0.104 & $(0.163)$ & -0.636 & $(0.270)$ \\
\hline WM & 0.241 & $(0.273)$ & 0.216 & $(0.772)$ & 0.126 & $(0.022)$ & 0.369 & $(0.055)$ & -0.142 & $(0.183)$ & -0.493 & $(0.279)$ \\
\hline $\mathrm{E}$ & 0.259 & $(0.229)$ & 0.700 & $(0.677)$ & 0.131 & $(0.018)$ & 0.276 & $(0.041)$ & -0.086 & $(0.148)$ & -0.668 & $(0.285)$ \\
\hline $\mathrm{L}$ & 0.463 & $(0.26)$ & 0.633 & $(0.861)$ & 0.116 & $(0.022)$ & 0.328 & (0.039) & -0.062 & $(0.092)$ & -1.222 & $(0.292)$ \\
\hline SE & 0.411 & $(0.313)$ & -1.179 & $(0.998)$ & 0.068 & $(0.027)$ & 0.336 & $(0.052)$ & -0.216 & $(0.176)$ & -0.338 & $(0.337)$ \\
\hline SW & 0.138 & $(0.287)$ & 0.675 & $(0.800)$ & 0.144 & $(0.020)$ & 0.362 & $(0.043)$ & 0.042 & $(0.042)$ & -0.847 & $(0.337)$ \\
\hline
\end{tabular}

\section{A. Results of regression of the core explanatory variables and their noisy signals on housing returns}


B. Overconfidence in the signals of the core explanatory variables

\begin{tabular}{|c|c|c|c|c|c|c|c|c|c|}
\hline & \multicolumn{3}{|c|}{ Stock market returns } & \multicolumn{3}{|c|}{ Consumption changes } & \multicolumn{3}{|c|}{ Human capital changes } \\
\hline & Overconfidence & Delta ratio & t stat & Overconfidence* & Delta ratio & $t$ stat & Overconfidence* & Delta ratio & $t$ stat \\
\hline Pooled & -2.819 & 29.818 & 0.43 & 0.020 & 0.318 & -6.07 & 1.020 & 0.080 & 2.14 \\
\hline UK & 1.477 & -14.100 & 0.50 & 0.019 & 0.334 & -6.77 & 1.024 & 0.087 & 2.61 \\
\hline NE & 0.112 & -0.143 & 1.28 & 0.023 & 0.199 & -4.25 & 0.776 & 0.279 & 0.40 \\
\hline NW & 0.154 & -0.571 & 1.38 & 0.020 & 0.299 & -4.60 & 1.545 & -0.431 & 0.87 \\
\hline $\mathrm{YH}$ & 0.507 & -4.186 & 0.80 & 0.023 & 0.214 & -5.62 & 1.261 & -0.110 & 1.74 \\
\hline EM & 0.010 & 0.899 & -0.03 & 0.020 & 0.319 & -4.96 & 0.924 & 0.164 & 1.69 \\
\hline WM & -0.011 & 1.117 & 0.03 & 0.019 & 0.341 & -4.11 & 0.788 & 0.288 & 1.05 \\
\hline E & 0.062 & 0.369 & -0.62 & 0.015 & 0.474 & -3.24 & 1.001 & 0.129 & 1.81 \\
\hline $\mathrm{L}$ & 0.026 & 0.732 & -0.19 & 0.019 & 0.355 & -4.73 & 1.119 & 0.051 & 3.78 \\
\hline SE & 0.132 & -0.349 & 1.52 & 0.023 & 0.202 & -4.59 & 0.392 & 0.639 & 0.32 \\
\hline SW & 0.078 & 0.205 & -0.63 & 0.017 & 0.397 & -4.60 & 1.180 & -0.049 & 2.62 \\
\hline
\end{tabular}




\section{Table 6. The biased coefficients and the unbiased coefficients}

This table reports the effects of overconfidence biases on the regression coefficients in panel A, the biased coefficients of housing returns on the signals of the three core explanatory variables in panel B, and the bias-free coefficients in panel C. Panel A shows degree of distortion in the coefficients of housing returns on the signals. The degree of distortion, i.e., $\left(\gamma_{i \bullet t}^{*}-\gamma_{i_{\bullet}}^{\prime}\right) / \gamma_{i_{\bullet} t}^{\prime}$, is estimated as in equation (13) using the overconfidence measures reported in panel $\mathrm{B}$ of Table 5. Panel B reports the regression results of equation (19). The lagged housing returns are included for the persistence of the housing returns. Panel $\mathrm{C}$ reports the unbiased coefficients of housing returns on the signals, which is calculated using the biased coefficients in panel B divided by $1+$ the ratios in panel A.

\section{A. The effects of overconfidence on coefficients - the ratios of the biased and unbiased coefficients}

\begin{tabular}{cccccccccccc} 
& Pooled & UK & NE & NW & YH & EM & WM & E & L & SE & SW \\
\hline Stock market returns & $-96.6 \%$ & $-107.1 \%$ & $-801.7 \%$ & $-275.2 \%$ & $-123.9 \%$ & $11.2 \%$ & $-10.5 \%$ & $170.7 \%$ & $36.7 \%$ & $-386.8 \%$ & $388.8 \%$ \\
Consumption changes & $214.3 \%$ & $199.3 \%$ & $403.8 \%$ & $234.7 \%$ & $368.0 \%$ & $213.9 \%$ & $193.2 \%$ & $111.0 \%$ & $181.8 \%$ & $396.0 \%$ & $152.0 \%$ \\
Household income changes & $1145.5 \%$ & $1051.1 \%$ & $258.3 \%$ & $-332.1 \%$ & $-1008 \%$ & $511.1 \%$ & $247.7 \%$ & $676.7 \%$ & $1867.2 \%$ & $56.5 \%$ & $-2129 \%$ \\
\hline
\end{tabular}

B. Regression coefficients on noisy signals of the three core explanatory variables

\begin{tabular}{|c|c|c|c|c|c|c|c|c|c|c|c|}
\hline & Pooled & UK & NE & $\mathbf{N W}$ & YH & EM & WM & $\mathbf{E}$ & $\mathbf{L}$ & SE & SW \\
\hline \multirow{2}{*}{ constant } & -0.003 & 0.000 & -0.005 & -0.003 & -0.004 & -0.003 & -0.002 & -0.002 & 0.000 & -0.004 & -0.001 \\
\hline & $(0.001)$ & $(0.001)$ & $(0.003)$ & $(0.002)$ & $(0.002)$ & $(0.002)$ & $(0.002)$ & $(0.002)$ & $(0.002)$ & $(0.002)$ & $(0.002)$ \\
\hline \multirow{2}{*}{ Noisy signal for stock returns } & 0.002 & 0.007 & -0.015 & -0.004 & 0.001 & 0.007 & 0.006 & 0.009 & 0.010 & -0.012 & 0.009 \\
\hline & $(0.005)$ & $(0.004)$ & $(0.008)$ & $(0.006)$ & $(0.008)$ & $(0.006)$ & $(0.006)$ & $(0.006)$ & $(0.006)$ & $(0.006)$ & $(0.005)$ \\
\hline \multirow{2}{*}{ Noisy signal for consumption changes } & 0.431 & 0.105 & 0.686 & 0.429 & 0.459 & 0.439 & 0.271 & 0.340 & 0.364 & 0.422 & 0.169 \\
\hline & $(0.089)$ & $(0.099)$ & $(0.168)$ & $(0.134)$ & $(0.158)$ & $(0.157)$ & $(0.116)$ & $(0.157)$ & $(0.159)$ & $(0.118)$ & $(0.126)$ \\
\hline \multirow{2}{*}{ Noisy signal for household income changes } & -0.046 & -0.046 & -0.027 & -0.018 & -0.030 & -0.055 & -0.033 & -0.054 & -0.086 & -0.046 & -0.052 \\
\hline & $(0.015)$ & $(0.014)$ & $(0.027)$ & $(0.019)$ & $(0.025)$ & $(0.018)$ & $(0.020)$ & $(0.034)$ & $(0.023)$ & $(0.019)$ & $(0.024)$ \\
\hline \multirow{2}{*}{ Lagged dependent variables } & 0.398 & 0.700 & 0.091 & 0.439 & 0.439 & 0.456 & 0.574 & 0.455 & 0.405 & 0.125 & 0.629 \\
\hline & $(0.063)$ & $(0.080)$ & $(0.124)$ & $(0.121)$ & $(0.121)$ & $(0.105)$ & $(0.133)$ & $(0.152)$ & $(0.101)$ & $(0.095)$ & $(0.103)$ \\
\hline $\mathrm{AuJ}_{\mathrm{J}} \mathrm{n}$ & $40.7 \%$ & $69.6 \%$ & $21.5 \%$ & $44.5 \%$ & $41.4 \%$ & $49.1 \%$ & $52.5 \%$ & $41.8 \%$ & $50.1 \%$ & $29.5 \%$ & $59.2 \%$ \\
\hline
\end{tabular}


C. Estimation of the unbiased coefficients - free from overconfidence

\begin{tabular}{cccccccccccc} 
& Pooled & UK & NE & NW & YH & EM & WM & E & L & SE & SW \\
\hline Noisy signal for stock returns & 0.054 & -0.093 & 0.002 & 0.002 & -0.004 & 0.006 & 0.007 & 0.003 & 0.007 & 0.004 & 0.002 \\
Noisy signal for consumption changes & 0.137 & 0.035 & 0.136 & 0.128 & 0.098 & 0.140 & 0.093 & 0.161 & 0.129 & 0.085 & 0.067 \\
Noisy signal for household income changes & -0.004 & -0.004 & -0.007 & 0.008 & 0.003 & -0.009 & -0.009 & -0.007 & -0.004 & -0.029 & 0.003 \\
\hline
\end{tabular}




\section{Table 7. Comparison of housing returns}

Panel A reports realized housing returns. Panel B represents average returns of overconfidence bias corrected returns calculated with the coefficients in panel $\mathrm{C}$ of Table 6 . The average returns in Panel $\mathrm{C}$ are those estimated with the coefficients biased by the overconfidence in panel B of Table 5 . The numbers in the round brackets are standard errors of the average returns.

\begin{tabular}{|c|c|c|c|c|c|c|c|c|c|c|}
\hline & UK & NE & NW & YH & EM & WM & $\mathrm{E}$ & $\mathrm{L}$ & SE & SW \\
\hline \multicolumn{11}{|c|}{ A. Realized housing returns } \\
\hline \multirow{2}{*}{$\begin{array}{c}\text { The Entire } \\
\text { Period }\end{array}$} & $1.575 \%$ & $1.463 \%$ & & $1.436 \%$ & $1.598 \%$ & $1.531 \%$ & $1.620 \%$ & $1.937 \%$ & $1.403 \%$ & $1.655 \%$ \\
\hline & $(0.260 \%)$ & $(0.297 \%)$ & $(0.240 \%)$ & $(0.290 \%)$ & $(0.267 \%)$ & $(0.243 \%)$ & $(0.288 \%)$ & $(0.265 \%)$ & $(0.203 \%)$ & $(0.249 \%)$ \\
\hline \multirow{2}{*}{1980 's } & $2.786 \%$ & $2.589 \%$ & $2.627 \%$ & $2.875 \%$ & $3.121 \%$ & $2.795 \%$ & $3.031 \%$ & $2.996 \%$ & $2.128 \%$ & $2.909 \%$ \\
\hline & $(0.502 \%)$ & $(0.541 \%)$ & $(0.488 \%)$ & $(0.564 \%)$ & $(0.562 \%)$ & $(0.546 \%)$ & $(0.602 \%)$ & $(0.400 \%)$ & $(0.312 \%)$ & $(0.503 \%)$ \\
\hline \multirow{2}{*}{1990 's } & $0.364 \%$ & $0.253 \%$ & $0.541 \%$ & $-0.199 \%$ & $0.098 \%$ & $0.387 \%$ & $0.199 \%$ & $0.898 \%$ & $0.633 \%$ & $0.469 \%$ \\
\hline & $(0.409 \%)$ & $(0.482 \%)$ & $(0.298 \%)$ & $(0.433 \%)$ & $(0.393 \%)$ & $(0.298 \%)$ & $(0.487 \%)$ & $(0.558 \%)$ & $(0.359 \%)$ & $(0.371 \%)$ \\
\hline \multirow{2}{*}{$2000 \mathrm{~s}$} & $2.046 \%$ & $2.153 \%$ & $2.075 \%$ & $2.235 \%$ & $2.037 \%$ & $1.879 \%$ & $1.957 \%$ & $1.925 \%$ & $2.107 \%$ & $2.046 \%$ \\
\hline & $(0.519 \%)$ & $(0.649 \%)$ & $(0.515 \%)$ & $(0.571 \%)$ & $(0.503 \%)$ & $(0.476 \%)$ & $(0.524 \%)$ & $(0.499 \%)$ & $(0.431 \%)$ & $(0.501 \%)$ \\
\hline \multirow{2}{*}{$2010 \mathrm{~s}$} & $0.648 \%$ & $0.251 \%$ & $0.231 \%$ & $0.241 \%$ & $0.706 \%$ & $0.614 \%$ & $1.006 \%$ & $1.977 \%$ & $0.052 \%$ & $0.751 \%$ \\
\hline & $(0.352 \%)$ & $(0.332 \%)$ & $(0.324 \%)$ & $(0.403 \%)$ & $(0.255 \%)$ & $(0.277 \%)$ & $(0.343 \%)$ & $(0.602 \%)$ & $(0.321 \%)$ & $(0.315 \%)$ \\
\hline
\end{tabular}

$\begin{array}{cccccccccccc}\text { B. Posterior expected housing returns free from overconfidence } & & & & & \\ \text { The Entire } & 1.370 \% & 1.149 \% & 1.260 \% & 1.048 \% & 1.334 \% & 1.345 \% & 1.482 \% & 1.845 \% & 1.229 \% & 1.638 \% \\ \text { Period } & (0.100 \%) & (0.092 \%) & (0.109 \%) & (0.091 \%) & (0.107 \%) & (0.107 \%) & (0.104 \%) & (0.108 \%) & (0.080 \%) & (0.102 \%) \\ 1980 ' s & 2.749 \% & 2.396 \% & 2.744 \% & 2.108 \% & 2.886 \% & 2.935 \% & 2.932 \% & 3.398 \% & 2.336 \% & 3.002 \% \\ & (0.068 \%) & (0.067 \%) & (0.072 \%) & (0.090 \%) & (0.074 \%) & (0.056 \%) & (0.077 \%) & (0.056 \%) & (0.065 \%) & (0.058 \%) \\ 1990 \text { 's } & 1.511 \% & 1.291 \% & 1.424 \% & 1.167 \% & 1.434 \% & 1.500 \% & 1.551 \% & 2.028 \% & 1.358 \% & 1.848 \% \\ & (0.096 \%) & (0.095 \%) & (0.114 \%) & (0.119 \%) & (0.084 \%) & (0.080 \%) & (0.091 \%) & (0.090 \%) & (0.077 \%) & (0.113 \%) \\ 2000 \mathrm{~s} & 0.721 \% & 0.565 \% & 0.611 \% & 0.673 \% & 0.586 \% & 0.495 \% & 0.859 \% & 1.050 \% & 0.651 \% & 1.001 \% \\ & (0.088 \%) & (0.081 \%) & (0.094 \%) & (0.108 \%) & (0.092 \%) & (0.077 \%) & (0.109 \%) & (0.077 \%) & (0.073 \%) & (0.081 \%) \\ 2010 \mathrm{~s} & -0.391 \% & -0.482 \% & -0.761 \% & -0.588 \% & -0.491 \% & -0.455 \% & -0.325 \% & -0.058 \% & -0.095 \% & -0.262 \% \\ & (0.060 \%) & (0.054 \%) & (0.061 \%) & (0.067 \%) & (0.069 \%) & (0.053 \%) & (0.085 \%) & (0.055 \%) & (0.055 \%) & (0.038 \%)\end{array}$

A. Realized housing returns

B. Posterior expected housing returns free from overconfidence

\begin{tabular}{|c|c|c|c|c|c|c|c|c|c|c|}
\hline \multicolumn{11}{|c|}{ C. Posterior expected housing returns affected by overconfidence } \\
\hline The Entire & $1.560 \%$ & $1.454 \%$ & $1.502 \%$ & $1.413 \%$ & $1.571 \%$ & $1.524 \%$ & $1.609 \%$ & $1.898 \%$ & $1.405 \%$ & $1.661 \%$ \\
\hline & $(0.128 \%)$ & $(0.141 \%)$ & $(0.134 \%)$ & $(0.139 \%)$ & $(0.144 \%)$ & $(0.121 \%)$ & $(0.127 \%)$ & $(0.129 \%)$ & & $(0.109 \%)$ \\
\hline \multirow[b]{2}{*}{ 1980's } & 2.74 & & & & & & & & & $1 \%$ \\
\hline & $(0.1$ & $(0.1$ & $(0.1$ & $(0.1$ & $(0.2$ & (0. & & & & \\
\hline \multirow{2}{*}{ 1990's } & 1.2 & 1.1 & & & & & & & & \\
\hline & $(0.1)$ & & & & & & & & & $1 \%)$ \\
\hline \multirow{2}{*}{$2000 \mathrm{~s}$} & $1.265 \%$ & $1.567 \%$ & $1.413 \%$ & $1.199 \%$ & $1.199 \%$ & 1.01 & $1.058 \%$ & 1.49 & $1.418 \%$ & $1.028 \%$ \\
\hline & $(0.235 \%)$ & $(0.290 \%)$ & $(0.253 \%)$ & & $(0.263 \%)$ & $\left(0.195^{\circ}\right.$ & & & & $(0.176 \%)$ \\
\hline \multirow[t]{2}{*}{$2010 \mathrm{~s}$} & $0.308 \%$ & $-0.006 \%$ & $-0.233 \%$ & $-0.270 \%$ & $0.276 \%$ & $0.014 \%$ & $0.365 \%$ & $1.247 \%$ & $0.430 \%$ & $0.950 \%$ \\
\hline & $(0.234 \%)$ & $(0.322 \%)$ & $(0.257 \%)$ & $(0.267 \%)$ & $(0.265 \%)$ & $(0.177 \%)$ & $(0.207 \%)$ & $(0.237 \%)$ & $(0.234 \%)$ & $(0.140 \%)$ \\
\hline
\end{tabular}




\section{Figure 1. Core explanatory variables and their noisy signals}

This figure shows stock market returns, consumption changes, and household income changes and their noisy signals obtained from the four steps described in section ??. Chart $\mathrm{C}$ shows UK household income changes rather than individual regional income changes for convenience.

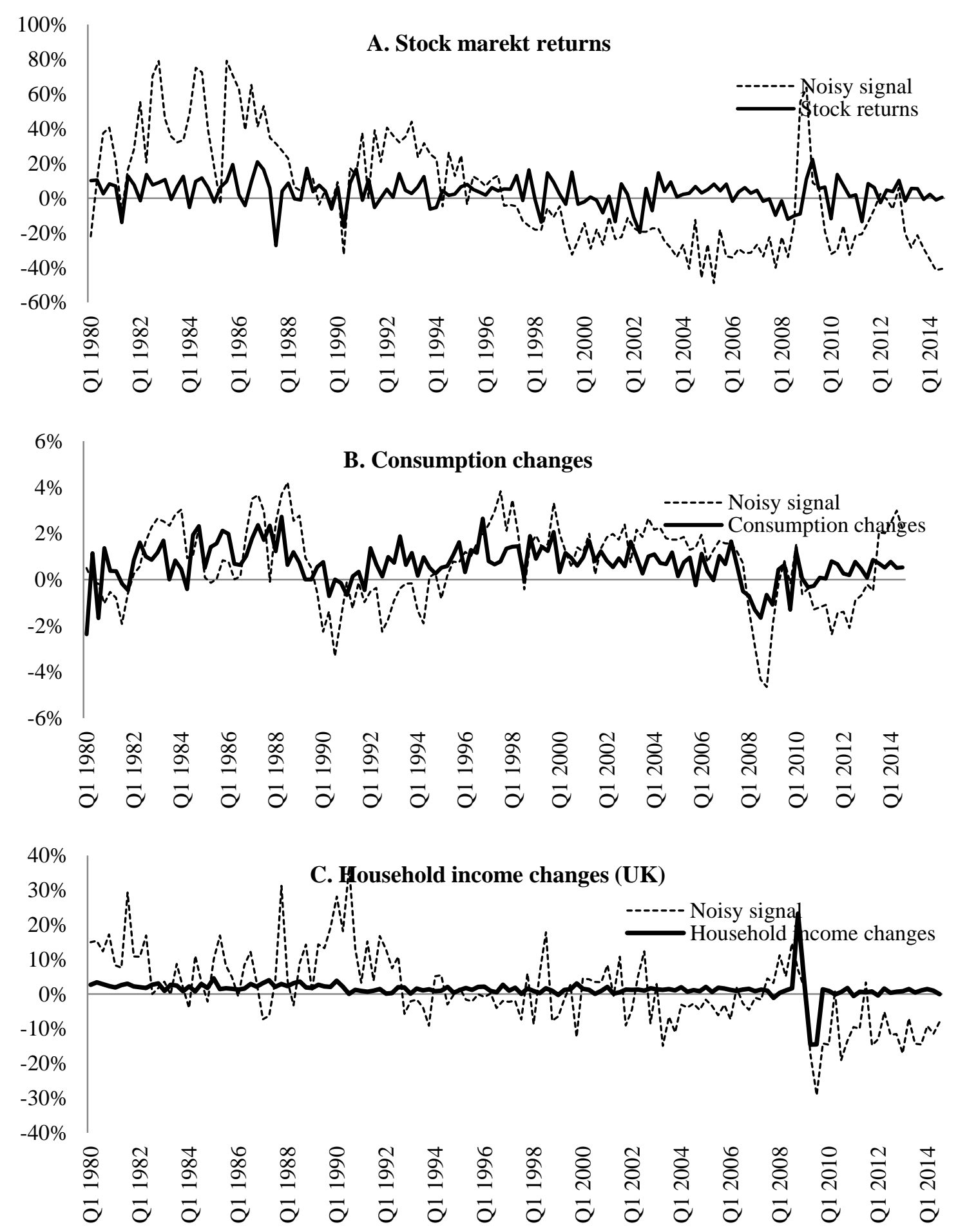


Figure 2. Expected housing return bias by household overconfidence

Biases in the expected housing returns are calculated by the difference between the housing returns predicted by posterior expectations of the three core variables and the housing returns predicted without overconfidence.

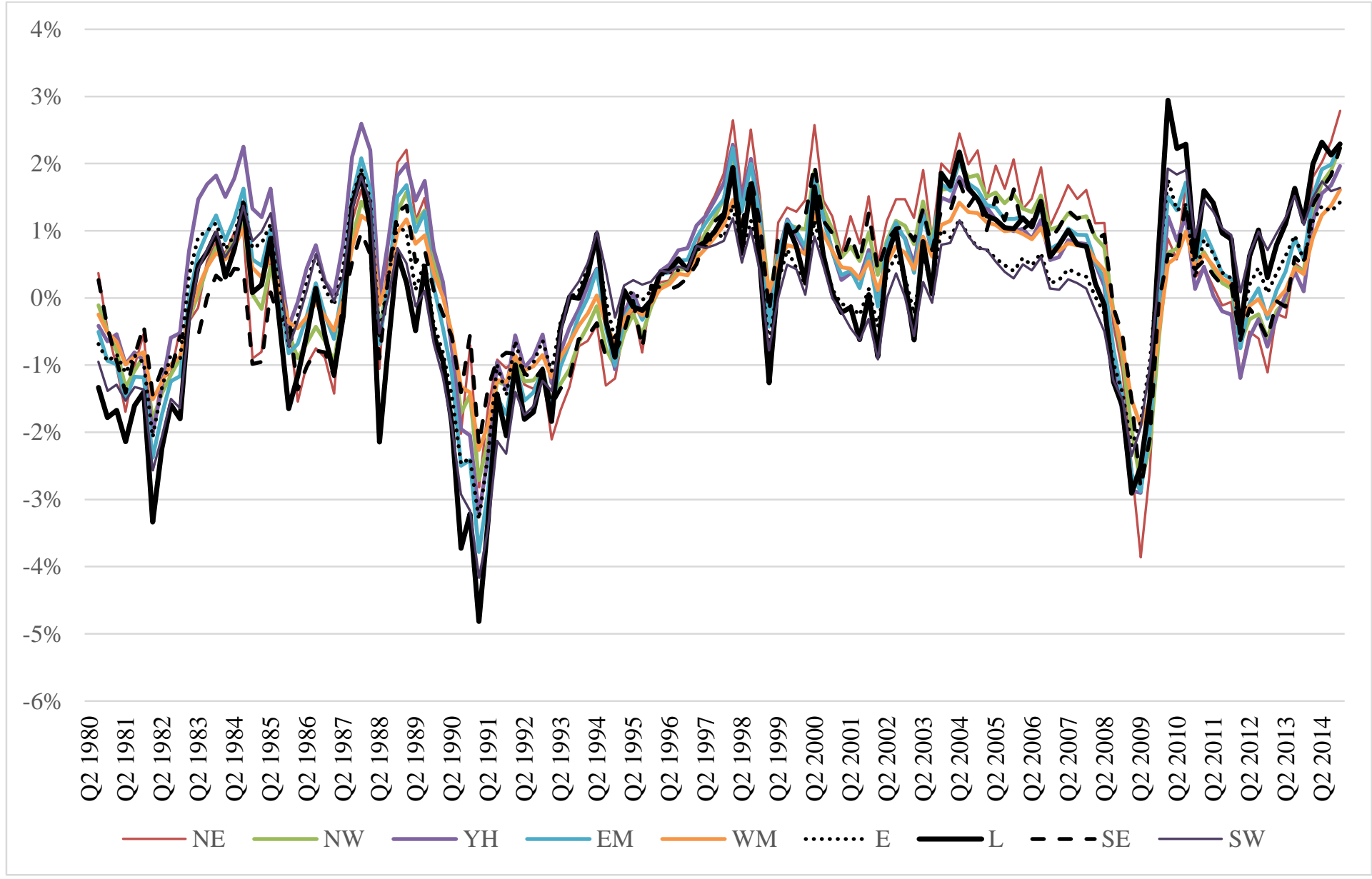


Figure 3. Comparison between cumulative expected excess returns with or without confidence biases

This figure compares cumulative returns predicted by posterior expectations of the three core variables and the cumulative realized housing returns.

UK

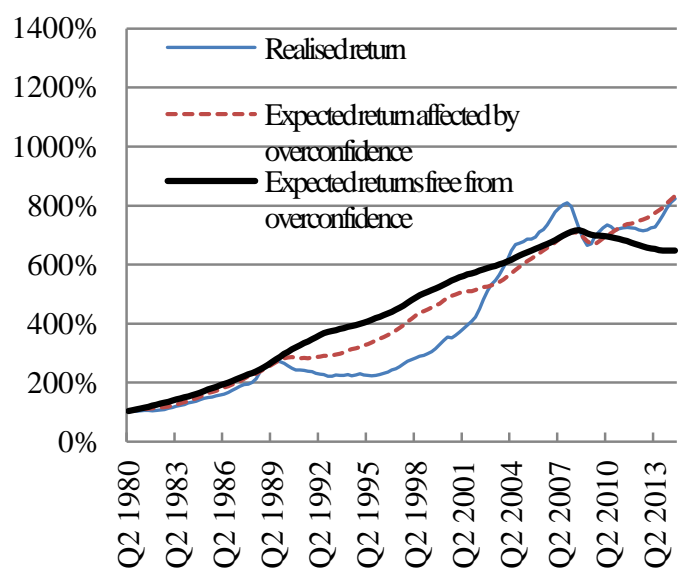

NW

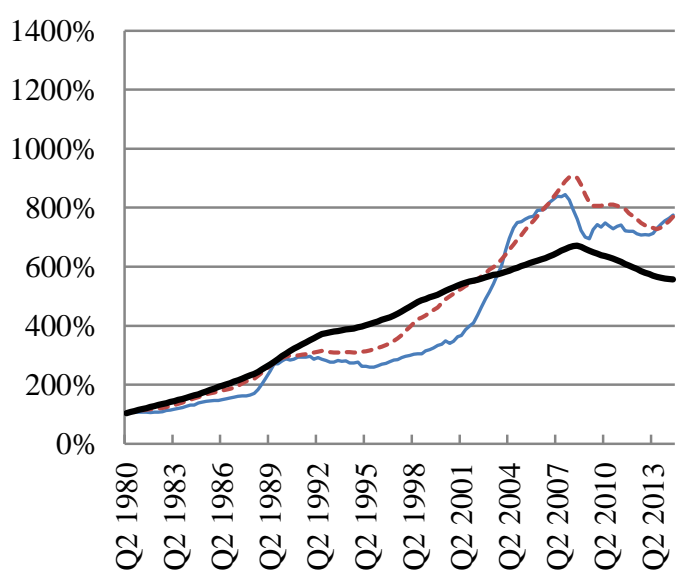

NE

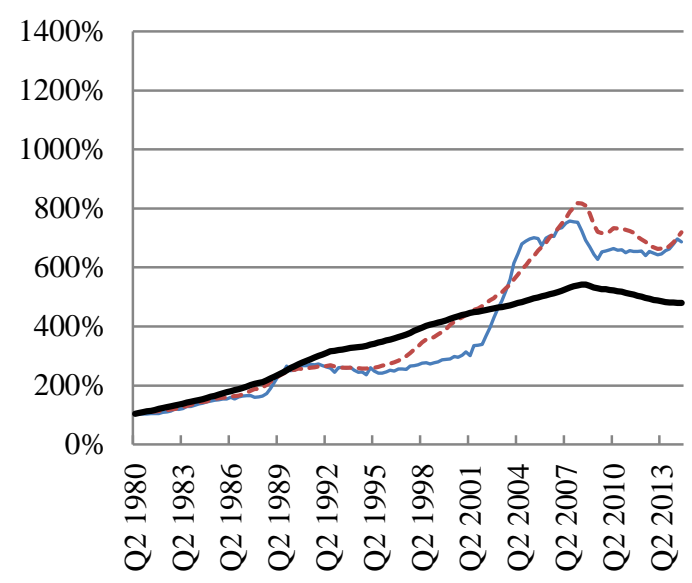

YH

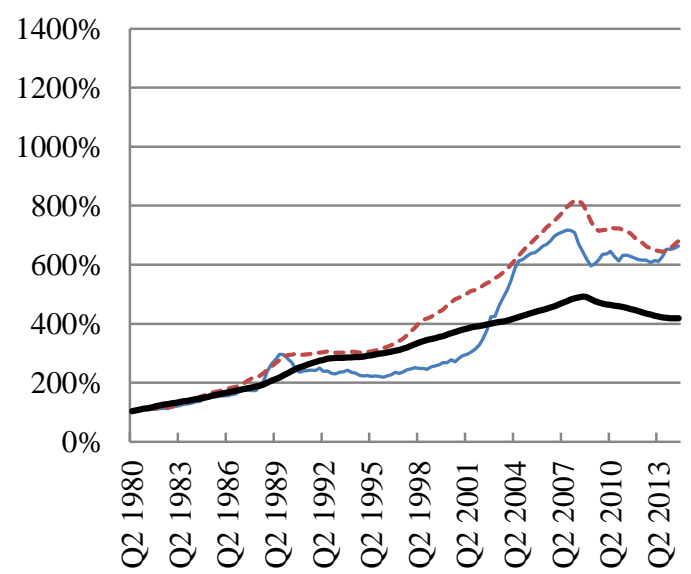


EM

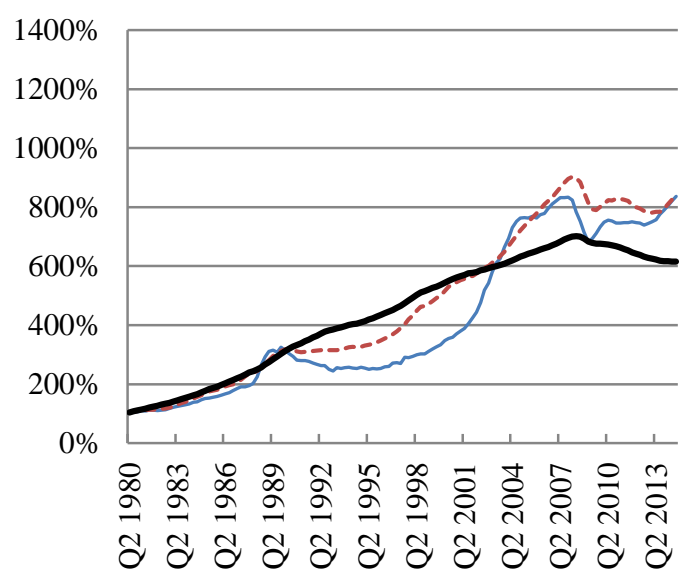

E

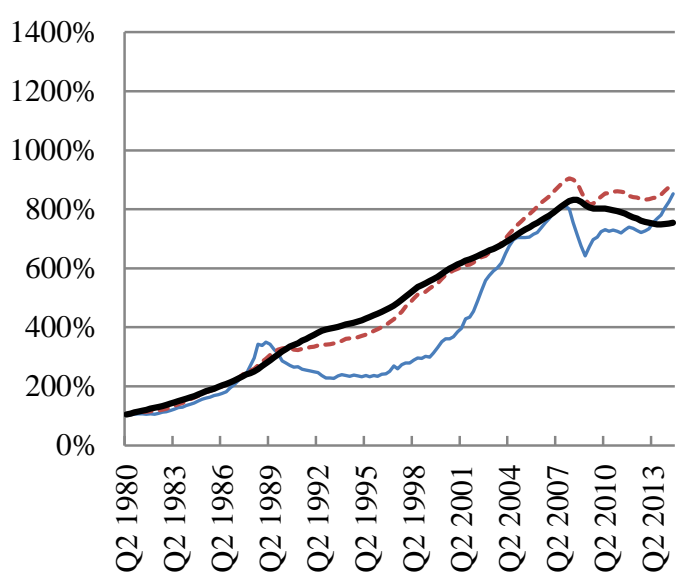

SE

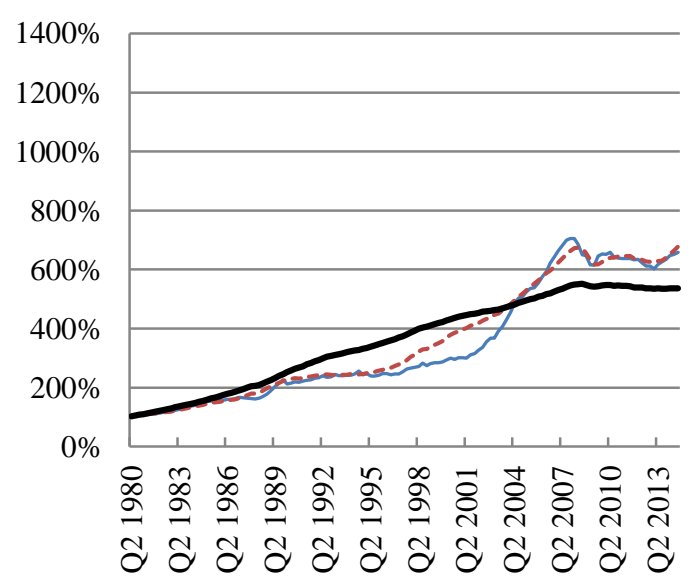

WM

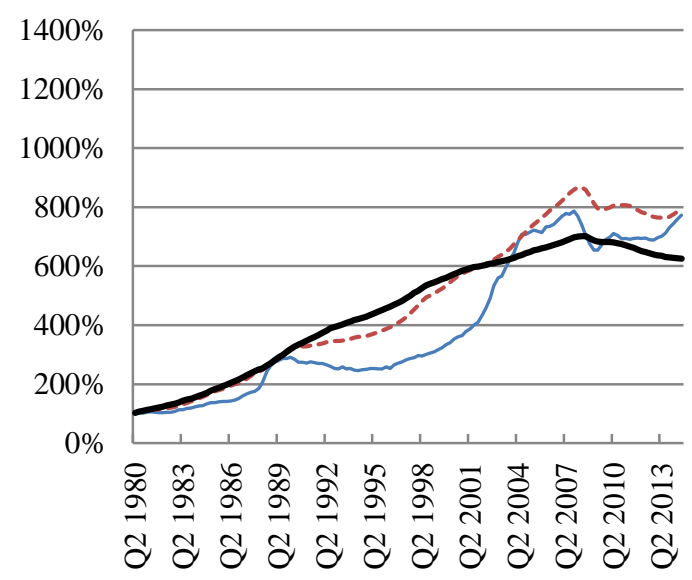

L

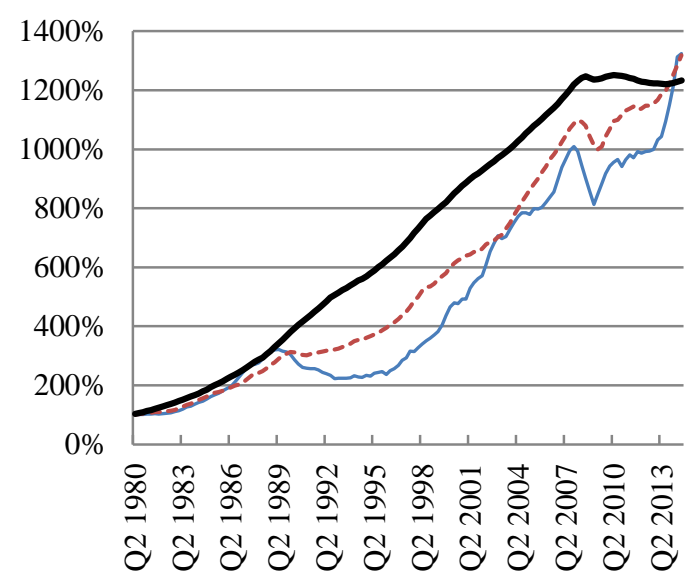

SW

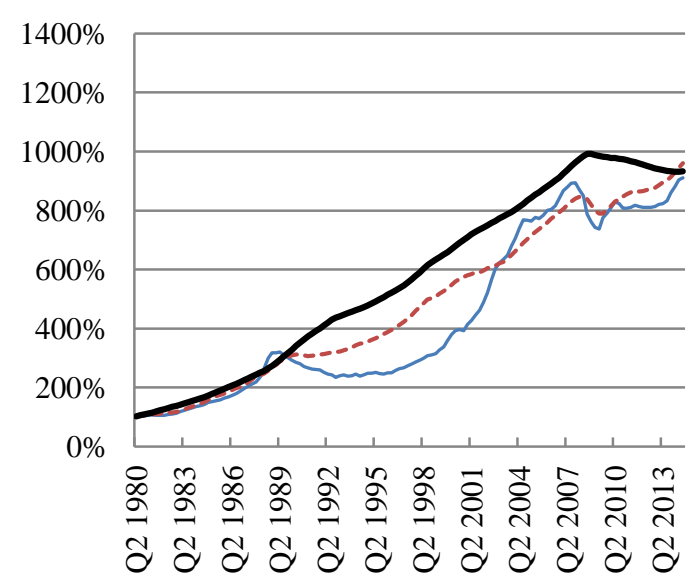

